\title{
Helminth communities from two urban rat populations in Kuala Lumpur, Malaysia
}

\author{
Siti N Mohd Zain ${ }^{1}$, Jerzy M Behnke ${ }^{2^{*}}$ and John W Lewis ${ }^{3}$
}

\begin{abstract}
Background: The prevalence of parasitic infections among commensal animals such as black and brown rats in many tropical countries is high and in comparison with studies on rodents in temperate climates, little is known about the community structure of their parasites. Rodent borne parasites pose threats to human health since people living in close proximity to rodent populations can be exposed to infection.

Methods: The helminth community structures of two urban rat populations in Kuala Lumpur, Malaysia were investigated. The rats were from two contrasting sites in the city caught over a period of 21 months in 2000-2002.

Results: Eleven species of helminth parasites comprising seven nematodes (Heterakis spumosum, Mastophorus muris, Nippostrongylus brasiliensis, Syphacia muris, Pterygodermatites tani/whartoni, Gongylonema neoplasticum, Angiostrongylus malaysiensis), three cestodes (Hymenolepis (Rodentolepis) nana, H. diminuta and Taenia taeniaeformis) and one acanthocephalan (Moniliformis moniliformis) were recovered from 346 Rattus rattus and 104 R. norvegicus from two urban sites, Bangsar and Chow Kit, during 2000-2002. Rattus rattus harboured over 60\% of all helminths compared with $R$. norvegicus, although both host species played a dominant role in the different sites with, for example R. norvegicus at Bangsar and R. rattus at Chow Kit accounting for most of the nematodes. Overall $80 \%$ of rats carried at least one species of helminth, with the highest prevalences being shown by $\mathrm{H}$. diminuta (35\%), $\mathrm{H}$. spumosum (29.8\%) and H. nana (28.4\%). Nevertheless, there were marked differences in prevalence rates between sites and hosts. The influence of extrinsic (year, season and site) and intrinsic (species, sex and age) factors affecting infracommunity structure (abundance and prevalence of infection) and measures of component community structure were analyzed.
\end{abstract}

Conclusions: Since at least two species of rat borne helminths in Kuala Lumpur have the potential to infect humans, and these showed high prevalences in the rats, the assessment and regular monitoring of infections carried by wild rodents have important roles to play in public health.

Keywords: Rattus norvegicus, Rattus rattus, helminths, nematodes, helminth species diversity, Hymenolepis diminuta, Hymenolepis nana, Mastophorus muris, Nippostrongylus brasiliensis, Heterakis spumosum

\section{Background}

The prevalence of parasitic infections among commensal animals in many tropical countries is high and poses threats to human health since people living in close proximity to rodent populations that act as reservoirs of infection, or to secondary hosts, can be exposed to infection. An extreme example of this is given by bubonic plague, the causative bacterium Yersinia pestis being

\footnotetext{
* Correspondence: jerzy.behnke@nottingham.ac.uk

${ }^{2}$ School of Biology, University of Nottingham, University Park, Nottingham NG7 2RD, UK

Full list of author information is available at the end of the article
}

transmitted by rat fleas, but there are many other examples of human diseases that have their origins in commensal rodent populations (e.g. Weil's disease, etc.) including helminths (e.g. trichinosis) [1-5]. Assessment and regular monitoring of infections carried by wild rodents therefore, have important roles to play in public health.

European and N. American wild rodents have been intensively investigated over the last decades with respect to their parasitic infections [6-12], but in comparison the parasite populations of wild rodents from the Far East have been poorly documented, and very

\section{Biomed Central}


little is known about their ecology and epidemiology. Several projects in Europe and the USA have focused on the factors that affect parasite communities including biogeography and abiotic parameters as well as host density and life history [9-14]. However, most studies of rodent parasites from the Far East are little more than species lists, and records of overall prevalence of species [15-27] with differing habitats and relatively small sample sizes [28]. To date there have been no comprehensive studies relating factors responsible for variation in parasite burdens of rodent communities in Malaysia nor any studying helminth communities over an extended period of time in this region.

The two dominant commensal rat species, the brown rat (Rattus norvegicus) and the black rat ( $R$. rattus), are distributed worldwide [29]. Both rodents inhabit urban cities, being commonly found around dumpsites, around cross-pits, in sewer systems and storm drains [30] and both have been well-studied because of their medical and economic importance [2].

Therefore, the objectives of the present work were to investigate the diversity of helminth parasites in two species of commensal rats ( $R$. rattus and $R$. norvegicus) from two urban sites in Kuala Lumpur. Additionally, the abundance of helminth species was monitored over a three year period, measures of component and infracommunity structure were calculated and interactions of helminth parasites with both intrinsic and extrinsic factors that are known to affect parasite abundance in other rodent species, were assessed. Of particular interest, was the relative role of these two rat species as hosts and reservoirs of the rodent helminth parasites endemic in the city, and particuarly those species that are transmissible to the human inhabitants of the city.

\section{Methods}

\section{Study sites}

Kuala Lumpur, the capital city of Malaysia is characterized by a tropical climate of high temperature and high humidity all year round with temperatures ranging between $30-36^{\circ} \mathrm{C}$ and with rainfall fairly even throughout most of the year but typically heavier during the monsoon season between October to February.

For the present work, the study sites were chosen based on the marked differences in the habitat and resources that they provide for rodents. Chow Kit $\left(03^{\circ} 09^{\prime} 53.75^{\prime \prime} \mathrm{N}\right.$, $\left.101^{\circ} 41^{\prime} 56.84^{\prime \prime} \mathrm{E}\right)$ is the largest wet market in Kuala Lumpur, a wet market being a fresh food market of a type commonly found in Asian countries. The name is derived from the extensive use of water in the markets in order to wash the floors, keep the fruits and vegetables fresh, and keep fish and shellfish alive. Traders sell an extensive range of raw food including fruits, vegetables, seafood and meat. Here, tons of rubbish are collected daily and deposited into several steel containers. Excess garbage falls to the ground forming temporary grounds for rats to forage in. In contrast, Bangsar (03 ${ }^{\circ}>50.78^{\prime \prime} \mathrm{N}, 101^{\circ} 40^{\prime}$ $19.05^{\prime \prime} \mathrm{E}$ ) is an affluent residential suburb on the outskirts of Kuala Lumpur with mixed residential sites. The hawker centres, restaurants and roadside stalls sell cooked food and rodents found here thrive on leftovers.

\section{Collection and examination of rats}

Rodents were trapped regularly by the vector control unit of the Kuala Lumpur Municipality (DBKL) as part of their rodent control measure. Rats were caught from both vicinities over a span of 4 days and 3 nights for 21 months in 2000-2002. Steel wire traps were used and were baited with tapioca and dried fish. Rats were removed alive from these traps and killed with chloroform prior to post mortem examination. They were examined immediately afterwards and morphometric measurements were taken, together with records of fur colour, to assist in distinguishing between the two species. The lengths of head and body, tail, hind foot and ear were recorded and with body weight, these parameters enabled the establishment of age classes.

A complete post-mortem was undertaken on freshly killed specimens, the alimentary tract together with its offshoots being carefully scrutinized for helminth parasites. When found, these were removed carefully, identified, counted and preserved in $70 \%$ ethanol.

\section{Age classes of rats}

Rats were allocated to three age classes on the basis of body weight, but since the two species differ markedly in adult weight, the ranges were different for each species. For $R$. norvegicus rats $<140 \mathrm{gm}$ in weight were allocated to age class one, those 140 to $<240$ gm into age class two, and age class three comprised rats $>240 \mathrm{gm}$. For $R$. rattus age class one comprised rats $<90$ gm, age class two 90 to $<150$, and age class three $>150 \mathrm{gm}$. The choice of the borderline between age class one and age class two for each species was based on MacDonald \& Barrett [29]. The remaining rats were divided into two approximately equal groups numerically, with the lighter half being considered as young but sexually mature adults, and the heavier half as older animals.

\section{Seasonal cycles}

The study was conducted across three calendar years (2000, 2001 and 2002), but local seasons did not fit conveniently within the January to December period. The dry season begins in March and extends to September, with the wet season occurring from October to February. Analyzing data with calendar year as a factor would have resulted in each year beginning and ending with a wet season, with the dry season in-between, and a split in the 
continuity of the wet season across the year divide. For this reason we fitted seasonal cycles rather than year as the more relevant factor, beginning with the dry season of seasonal cycle 1 and continued for 3 cycles, ending in the wet season of cycle 3 .

\section{Data analysis}

Prevalence data (percentage of animals infected) are shown with 95\% confidence limits (95\% CL, lower limit upper limit), calculated as described previously [31], using bespoke software and were analyzed by maximum likelihood techniques based on log linear analysis of contingency tables in the software package SPSS 16. These analyses were confined to helminths that showed an overall prevalence greater than $10 \%$. Initially, full factorial models incorporated host species (2 levels, $R$. norvegicus and $R$. rattus), seasonal cycle (3 levels, cycle 1, 2 and 3), site (2 levels, Chow Kit and Bangsar), season (2 levels, wet and dry season), sex (2 levels, males and females), age (3 age classes) and infection as a binary factor (present/absent). The backward selection procedure was implemented to derive minimum sufficient models for which the likelihood ratio of $\chi^{2}$ was not significant. The importance of each term (i.e. interactions involving infection) in the final model was assessed by the probability that its exclusion would alter the model significantly.

Because the analysis was based on seven factors (host, site, seasonal cycle, season, age, sex and presence/absence of infection), full factorial models were complex and therefore when relevant, a two stage analysis was adopted. First we explored the full factorial model seeking evidence that there was a difference between hosts, and if there was, we explored this further. Secondly we fitted models for each rat species in turn and examined all relevant interactions in these.

Helminth species richness was analyzed by GLM (with normal errors) in SPSS in a two step procedure, first fitting models that incorporated all factors, main effects and only 2-way interactions, for each host species in turn. These were simplified by the backward selection procedure, with stepwise removal of non significant terms, eventually deriving a minimum sufficient model that retained only the significant interactions, main effects associated with those interactions whether significant or not, and any additional significant main effects. Then, we added host species as an additional factor (2 levels, $R$. norvegicus and $R$. rattus) with all relevant 2 -way and 3-way interactions. These models were then simplified by the backward selection procedure until a minimum sufficient model was obtained, as above.

The degree of aggregation in the data was calculated by the index of discrepancy ( $D$ [32]) and the index of dispersion ( $I$, variance to mean ratio). Frequency distributions of individual taxa were also tested for goodness of fit to negative binomial, positive binomial and Poisson models by $\mathrm{Chi}^{2}$ [33].

For analysis of parasite abundance data, we first fitted generalized linear models with negative binomial errors in $\mathrm{R}$ version 2.2.1 ( $\mathrm{R}$ Core Development Team), using the glm.nb routine in the MASS library of $R$ [34]. All parametric models were checked for approximately normal or negative binomial distribution of residuals, and if the former did not conform to normal distribution, we transformed the raw data accordingly.

When neither of the above generated satisfactory models, we resorted to non-parametric tests, first examining each of the main effects in turn, either with the Mann-Whitney U test (2 levels) or the KruskalWallis test (3 levels) on the combined data-set from both species of rats, and then on each of the rat species in turn.

\section{Results}

\section{Hosts}

A total of 486 rats were autopsied including, $140 R$. norvegicus and $346 R$. rattus. Four other species were also encountered and these were $R$. argentiventus, $R$. annanda$l e i, R$. exulans and $R$. tiomanicus. None of these species exceeded $7 \%$ of the catch at either site and we do not report further on these species of Rattus in the current work. Table 1 shows the numbers by host species, site and age class. For $R$. norvegicus the sex ratio was close to 1 , with $52.9 \%$ males and $47.1 \%$ females. For $R$. rattus, more females were sampled (57.7\% females and $42.3 \%$ males). One rat was not sexed and was excluded from all analyses in which sex was a consideration. More of each species were caught in the dry season ( $R$. norvegicus $60.7 \%$ and $39.3 \%, R$. rattus 55.45 and $44.6 \%$ in dry and wet seasons, respectively), which was longer than the wet season (7 months compared with 5). Fewer of each species were caught in 2000 and most in 2001 ( $R$. norvegicus 12.9\%, $50.7 \%$ and $36.4 \%$, $R$. rattus $5.8 \%, 57.4 \%$ and $36.8 .0 \%$ in 2000, 2001 and 2002, respectively). However, the analyses were conducted in relation to seasonal cycles that enabled actual seasons to be fitted chronologically, ranging from March of each year to the following February. In this arrangement for $R$. norvegicus the percentages of rats in seasonal cycles 1, 2 and 3 were 17.9, 53.6 and $28.6 \%$ and for $R$. rattus, 13.9, 60.3 and $25.8 \%$, respectively. With six factors fitted (host species, season, cycle, site, sex and age), log-linear analysis revealed a complex model in which all factors played a significant role in 8 sets of interactions (five 3-way and three 2-way interactions, full model likelihood ratio $\chi_{100}^{2}=72.53, P=0.982$ ).

\section{Host age}

In order to confirm that the three age classes reflected the growth and aging of rats, i.e. increased with host age 
Table 1 Numbers of rats examined by species, site and age class

\begin{tabular}{|c|c|c|c|c|c|c|}
\hline \multirow[b]{2}{*}{ Species } & \multirow[b]{2}{*}{ Site } & \multicolumn{3}{|c|}{ Age class } & \multirow[b]{2}{*}{ Total } & \multirow[b]{2}{*}{ Total } \\
\hline & & Class 1 & Class 2 & Class 3 & & \\
\hline \multirow[t]{2}{*}{ R. norvegicus } & Chow Kit & 15 & 33 & 12 & 60 & 140 \\
\hline & Bangsar & 22 & 18 & 40 & 80 & \\
\hline \multirow[t]{2}{*}{ R. rattus } & Chow Kit & 38 & 119 & 128 & 285 & 345 \\
\hline & Bangsar & 11 & 23 & 26 & 60 & \\
\hline \multirow[t]{2}{*}{ Total by species } & R. norvegicus & 37 & 51 & 52 & 140 & 485 \\
\hline & R. rattus & 49 & 142 & 154 & 345 & \\
\hline \multirow[t]{2}{*}{ Total by site } & Chow Kit & 53 & 152 & 140 & 345 & 485 \\
\hline & Bangsar & 33 & 41 & 66 & 140 & \\
\hline Total & & 86 & 193 & 206 & & 485 \\
\hline
\end{tabular}

This table excludes one $R$. rattus that was not sexed

from age class 1 through to age class 3, we first conducted a Principal Components Analysis, fitting host weight, head and body length, tail length, hind foot length and ear length as separate components. For $R$. norvegicus Principal Component 1 (PC1) accounted for $61.5 \%$ of the variance and showed the expected positive correlation with each parameter in turn, ranging from $R=0.92$ for head + body length, to $R=0.442$ for ear length. For $R$. rattus PC1 accounted for $52.0 \%$ of the variance and showed positive correlations with each parameter ranging from $R=0.90$ for body weight to $R=$ 0.39 for ear length and increased markedly across the three age classes. In $R$. norvegicus, but not $R$. rattus, there was also a significant difference between the sexes $\left(F_{1,134}=4.54, P=0.035\right.$; for males mean PC1 $=0.293 \pm$ 0.114 , and for females $-0.329 \pm 0.114)$. With the exception of ear length, each parameter had the lowest mean in age class 1 and increased through to age class 3. Ear length increased from age class 1 to age class 2 but no further $\left(F_{2,475}=21.8, P<0.001\right)$. In all cases there was a significant difference between the host species, confirming that morphometric parameters were always higher in $R$. norvegicus compared with $R$. rattus (Figure 1). The rate of increase in body weight was higher across the three age classes in $R$. norvegicus compared with $R$. rattus (Figure 1A). For head plus body length there was a 2-way interaction between host species and sex arising from the body length being very similar in male and female $R$. rattus, but increasing more quickly in male compared with female $R$. norvegicus across the three age classes (Figure 1B). Hind foot length varied between the sexes $\left(F_{1,472}=33.6, P=0.001\right)$, means being consistently higher among males of both species, but the discrepancy between the sexes was higher among $R$. norvegicus compared with $R$. rattus (2-way interaction between host species and sex, $\left.F_{2,472}=39.6, P<0.001\right)$. Tail length also varied between the sexes across both species $\left(F_{1,471}=\right.$ 11.3, $P=0.001)$ but contrary to the other measures tail length was generally longer in females (data not shown).

\section{Regional helminth community structure}

The combined total of all helminths recovered in the survey was 13,800 with slightly more cestodes $(51.0 \%)$ than nematodes $(48.0 \%)$, and acanthocephala being poorly represented (1.0\%). When the percentage distribution of helminths was calculated, $R$. rattus harboured almost two thirds of all helminths compared with $R$. norvegicus, and this was similar across all the higher taxa, except for larval cestodes which were only found in $R$. rattus (Table 2).

Eleven species of helminths were identified, comprising 3 species of cestodes, two of which were adult intestinal forms and one larval, seven species of nematodes and 1 acanthocephalan (Table 3).

\section{Measures of component community structure}

The percentage distribution of helminths between the two sites was approximately equal when host sample size was taken into consideration, although in terms of actual worms recovered, more than three times as many came from the higher sample of rats from Chow Kit (Table 2). Over four times as many helminths were recovered from $R$. rattus compared with $R$. norvegicus in the raw data-set, but when we controlled for sample size the difference was almost two-fold (Table 2). Interestingly $R$. norvegicus trapped at Bangsar, and $R$. rattus at Chow Kit accounted for most of the nematodes, so the two host species each played a dominant role in one of the two sites in this context. About twice as many adult cestodes came from $R$. rattus compared with $R$. norvegicus, and this was consistent in both sites. However, all larval cestodes (Table 2) came from $R$. rattus in Chow Kit, and the majority of acanthocepahalans from $R$. rattus in Bangsar.

Of the eleven species of helminths identified (Table 3), the majority were shared by both rat species in both sites. All the species were recovered from $R$. rattus in Chow Kit, although four species (S. muris, G. neoplasticum, T. taeniaeformis and $A$. malaysiensis) were absent from Bangsar. The first three of these were not found in $R$. norvegicus at either site. 

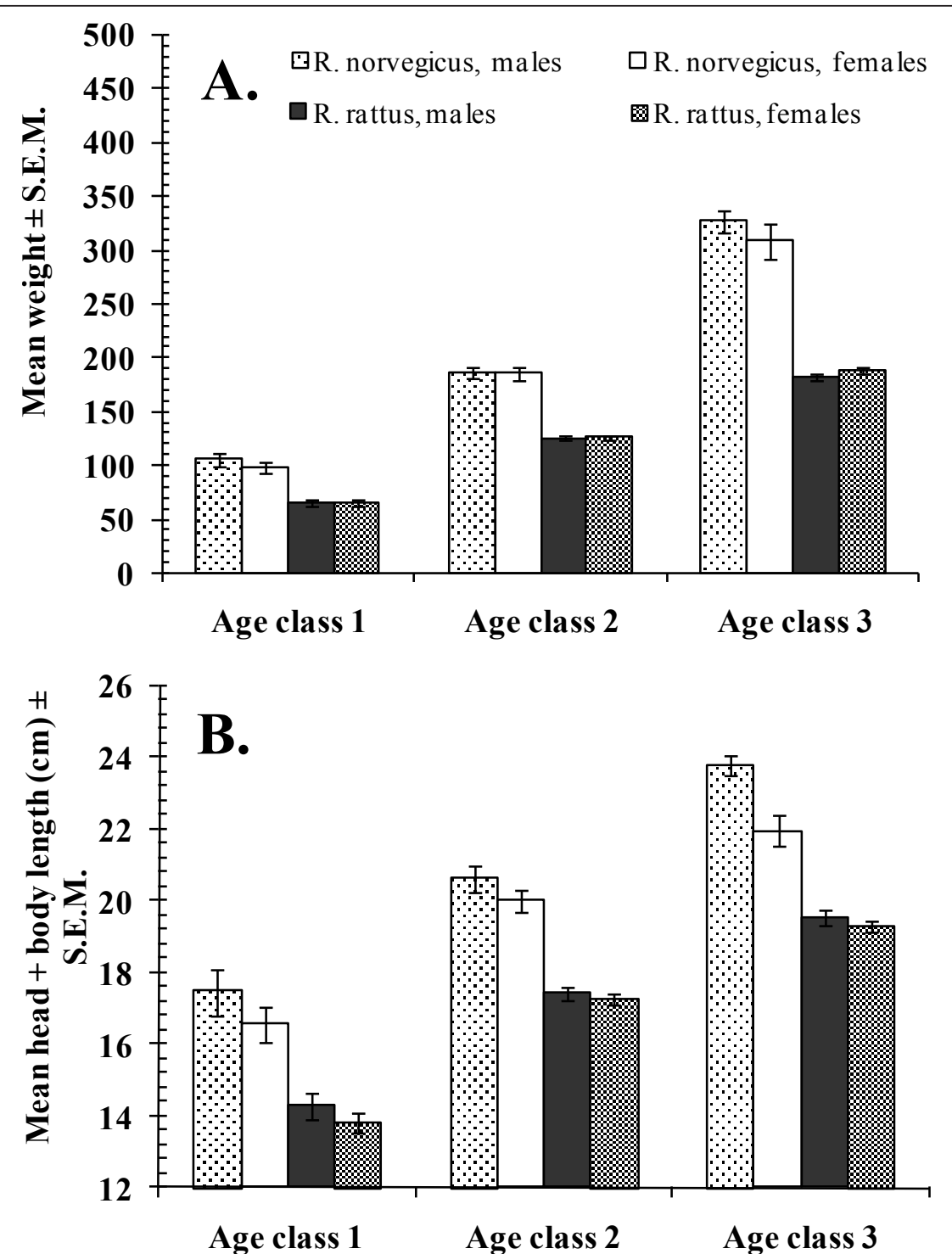

Figure 1 Analysis of morphometric measures in relation to the age classes. Rats were allocated to 3 age classes as described in the text. Body weight (A) where analysis was initially by 3-way GLM, but sex and its interactions were not significant and therefore was removed from the model. In a 2-way GLM with host species and age as factors, for main effect of host species $F_{1,479}=565.8, P<0.001$; for main effect of age $F_{2,479}=908.9, P<0.001$ and for the interaction $F_{2,479}=90.0, P<0.001$ and the model adjusted $R^{2}=0.83$; head and body length (B) where analysis is by 3-way GLM, with host species, sex and age as factors, and this gave for the main effects of host species $F_{1,477}=370.4, P<0.001$, age $F_{2,477}=337.5, P<0.001$, host sex $F_{1,477}=19.2, P<0.001$ and for the interaction between host species and sex $F_{1,479}=7.8, P=0.005$. No other interactions were significant with the model adjusted $R^{2}=0.68$.

Overall, $80.0 \%$ of rats harboured at least one helminth species (Table 3) with high prevalence values being shown by $H$. diminuta (36.1\%), H. spumosum (29.9\%) and $H$. nana (28.2\%). Nevertheless, there were marked differences in prevalence between sites and hosts.

Simpson's index of diversity was highest in $R$. rattus from Chow Kit, and lowest in $R$. rattus from Bangsar (Table 4). The overall value for Simpson's index of diversity was 0.740 , which is almost identical to that for $R$. rattus at
Chow Kit. Combining the data for both sites, the value of Simpson's was very similar for both species $(R$. rattus $=$ 0.727 and $R$. norvegicus $=0.729$ ), and combining rat species it was not markedly different between sites (Chow Kit = 0.744 and Bangsar $=0.697$ ).

The Berger-Parker dominance index was highest in $R$. rattus from Bangsar, where the dominant species was H. nana (Table 4). The remaining three combinations had very similar but lower Berger-Parker dominance indices, 
Table 2 Percentage distribution of higher taxa by host species and site

\begin{tabular}{|c|c|c|c|c|c|c|c|c|}
\hline & \multicolumn{6}{|l|}{ Host } & & \\
\hline & \multicolumn{2}{|c|}{ R. norvegicus } & \multicolumn{2}{|l|}{ R. rattus } & \multicolumn{2}{|c|}{ Hosts combined } & \multicolumn{2}{|c|}{ Sites combined } \\
\hline & Chow Kit & Bangsar & Chow Kit & Bangsar & Chow Kit & Bangsar & R. norvegicus & R. rattus \\
\hline All helminths as a \% of grand total* & 4.3 & 13.7 & 72.6 & 9.4 & 76.9 & 23.1 & 18.0 & 82.0 \\
\hline All helminths adjusted for sampling effort** & 10.9 & 26.3 & 38.9 & 24.0 & 49.8 & 50.3 & 37.2 & 62.9 \\
\hline Nematodes** & 7.1 & 38.3 & 47.2 & 7.4 & 54.3 & 45.7 & 45.4 & 54.6 \\
\hline Adult cestodes** & 13.5 & 17.7 & 33.5 & 35.2 & 47.0 & 52.9 & 31.2 & 68.7 \\
\hline Larval cestodes** & 0 & 0 & 100 & 0 & 100 & 0 & 0 & 100 \\
\hline Acanthocephala** & 17.4 & 12.3 & 10.8 & 59.5 & 28.2 & 71.8 & 29.7 & 70.3 \\
\hline
\end{tabular}

* Values based on total number of helminths recovered from each site without adjustment for sample size

** Percentage distribution calculated with sample size taken into consideration

and in two of these $H$. nana was also the dominant species. However, in $R$. norvegicus from Bangsar N. brasiliensis was the dominant species.

\section{Measures of infracommunity structure Mean species richness}

The overall mean number of helminth species harboured per host (all rats combined, $\mathrm{n}=485$ ) was $1.4 \pm$ 0.05 (variance to mean ratio $=0.77$ ). Analysis of helminth species richness restricted to $R$. norvegicus revealed only one significant 2-way interaction, seasonal cycle ${ }^{*}$ season $\left(F_{2,134}=6.1, P=0.003\right)$. Mean species richness was higher in 2 wet seasons (cycles 2 and 3 ), but lower in the wet season of cycle 1 compared with the preceding dry season (Figure 2A).

For $R$. rattus a similar 2-way interaction was highly significant (seasonal cycle* season, $F_{2}, 336=7.57, P=0.001$ ) and the pattern of change was much the same in seasonal cycles 1 and 2, but not in cycle 3, when mean helminth species richness was higher in the dry season compared to the wet season much as in cycle 1 (Figure 2A). There were also two marginally significant main effects in $R$. rattus; mean helminth species richness was lower at Bangsar compared with Chow Kit (Table 5, $F_{1}$, $336=4.03, P=$ 0.046), and increased with age, but then leveled off in age class $3\left(F_{1,336}=3.23, P=0.041\right.$, values in age classes $1-3$, = $1.18 \pm 0.145,1.69 \pm 0.092,1.53 \pm 0.087$, respectively) Neither the effect of site nor host age proved significant in the case of $R$. norvegicus. With respect to site, the trend was in the opposite direction to that in $R$. rattus although less marked (Table 5), and similarly in relation to age, the increase with age was delayed relative to $R$. rattus (mean helminth species richness in age classes $1-3,=1.03 \pm$ $0.142,1.06 \pm 0.123,1.23 \pm 0.118$, respectively).

To determine whether helminth species richness varied significantly between hosts, the significant effects

Table 3 Prevalence (\% of hosts infected) of helminth taxa by host species and site

\begin{tabular}{|c|c|c|c|c|c|c|}
\hline \multirow[b]{3}{*}{ Taxon } & \multirow[b]{3}{*}{ Species } & \multicolumn{4}{|l|}{ Species } & \multirow[b]{3}{*}{ Combined } \\
\hline & & \multicolumn{2}{|c|}{ R. norvegicus } & \multicolumn{2}{|l|}{ R. rattus } & \\
\hline & & Chow Kit & Bangsar & Chow Kit & Bangsar & \\
\hline \multirow[t]{7}{*}{ Nematodes } & Mastophorus muris & 21.7 & 3.8 & 22.8 & 8.3 & 17.7 \\
\hline & Syphacia muris & 0 & 0 & 12.3 & 0 & 7.2 \\
\hline & Nippostrongylus brasiliensis & 1.7 & 17.5 & 20.0 & 13.3 & 16.5 \\
\hline & Gongylonema neoplasticum & 0 & 0 & 0.7 & 0 & 0.4 \\
\hline & Pterygodermatites whartoni/tani & 1.7 & 3.8 & 4.6 & 5.0 & 4.1 \\
\hline & Heterakis spumosum & 18.3 & 18.8 & 37.9 & 18.3 & 29.9 \\
\hline & Angiostrongylus malaysiensis & 1.7 & 1.3 & 1.4 & 0 & 1.2 \\
\hline All nematodes & & 38.3 & 36.3 & 67.4 & 40.0 & 55.3 \\
\hline \multirow[t]{3}{*}{ Cestodes } & Hymenolepis diminuta & 28.3 & 57.5 & 32.3 & 33.3 & 36.1 \\
\hline & Hymenolepis nana & 21.7 & 21.3 & 29.8 & 36.7 & 28.2 \\
\hline & Taenia taeniaeformis & 0 & 0 & 1.4 & 0 & 0.8 \\
\hline All adult cestodes & & 48.3 & 71.3 & 58.2 & 68.3 & 60.8 \\
\hline All larval cestodes & & 0 & 0 & 1.4 & 0 & 0.8 \\
\hline All cestodes & & 48.3 & 71.3 & 58.9 & 68.3 & 60.8 \\
\hline Acanthocephala & Moniliformis moniliformis & 8.3 & 10.0 & 8.1 & 8.3 & 8.5 \\
\hline All helminths & & 66.7 & 81.3 & 82.5 & 80.0 & 80.0 \\
\hline
\end{tabular}




\begin{tabular}{|c|c|c|c|c|}
\hline & \multicolumn{4}{|l|}{ Species } \\
\hline & \multicolumn{2}{|c|}{ R. norvegicus } & \multicolumn{2}{|l|}{ R. rattus } \\
\hline & Chow Kit & Bangsar & Chow Kit & Bangsar \\
\hline Total no. of helminth species identified & 8 & 8 & 11 & 7 \\
\hline Berger-Parker dominance index & 0.499 & 0.523 & 0.401 & 0.700 \\
\hline Dominant species & H. nana & N. brasiliensis & H. nana & H. nana \\
\hline Simpson's index of diversity & 0.676 & 0.652 & 0.741 & 0.487 \\
\hline
\end{tabular}

from each model were then re-analyzed in a restricted model, incorporating host species as an additional factor, and fitting all interaction terms. The 2 -way cycle*season interaction emerged the strongest $\left(F_{2,473}=12.57\right.$, $P<0.001$, Figure 2A) but the seasonal effect differed significantly between hosts (2-way interaction host"season, $\left.F_{1}, 473=5.98, P=0.015\right)$, because when the cycles were combined there was still a marked seasonal difference in the mean helminth species richess in $R$. norvegicus, but not in $R$. rattus (Figure 2B). In particular, mean
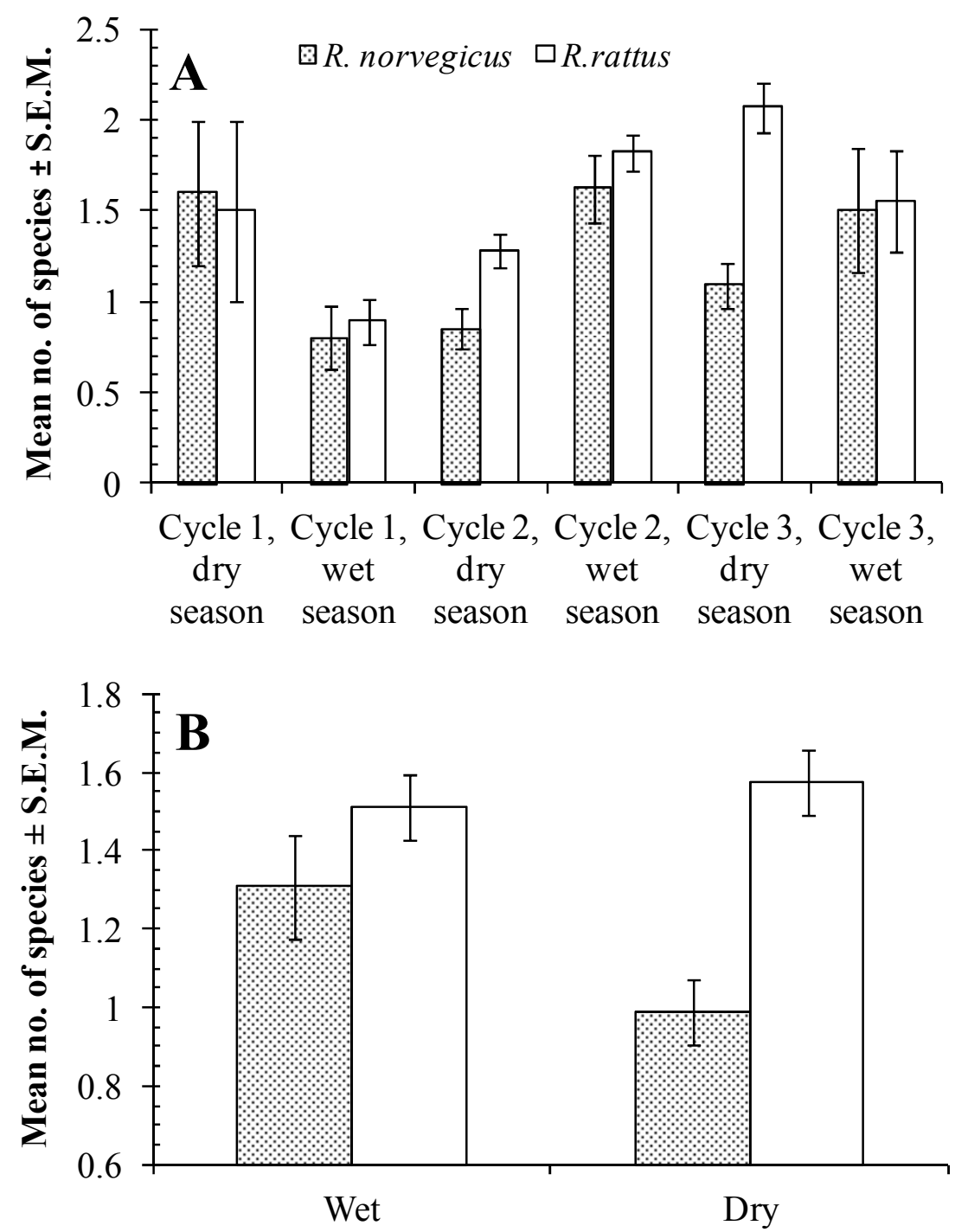

Season

Figure 2 Variation in helminth species richness. Cyclical and seasonal variation in both hosts (A) and seasonal variation between hosts (B). 
Table 5 Measures of infracommunity structure by host species and site

\begin{tabular}{|c|c|c|c|c|}
\hline & \multicolumn{4}{|l|}{ Species } \\
\hline & \multicolumn{2}{|l|}{ R. norvegicus } & \multicolumn{2}{|l|}{ R. rattus } \\
\hline & Chow Kit & Bangsar & Chow Kit & Bangsar \\
\hline Mean number of species \pm S.E.M. & $0.950 \pm 0.110$ & $1.238 \pm 0.096$ & $1.633 \pm 0.067$ & $1.150 \pm 0.100$ \\
\hline Maximum number of species & 3 & 3 & 5 & 3 \\
\hline Mean number of helminths \pm S.E.M. & $9.8 \pm 2.29$ & $23.7 \pm 5.60$ & $35.0 \pm 4.3$ & $21.6 \pm 5.37$ \\
\hline Mean number of nematodes \pm S.E.M. & $2.7 \pm 0.96$ & $14.6 \pm 4.83$ & $17.9 \pm 3.45$ & $2.8 \pm 0.75$ \\
\hline Mean number of cestodes \pm S.E.M. & $6.8 \pm 2.14$ & $9.0 \pm 2.22$ & $16.9 \pm 2.43$ & $17.8 \pm 4.94$ \\
\hline Mean Brillouin's index \pm S.E.M. & $0.127 \pm 0.031$ & $0.166 \pm 0.029$ & $0.247 \pm 0.016$ & $0.147 \pm 0.031$ \\
\hline Maximum Brillouin's index & 0.850 & 0.930 & 1.170 & 1.050 \\
\hline
\end{tabular}

species richness was high in $R$. rattus compared with $R$. norvegicus during the dry seasons of cycles 2 and 3 (Figure 2A).

There was also a significant difference between the rat species (main effect of host, $F_{1,473}=6.44, P=0.011$, $R$. norvegicus $=1.11 \pm 0.073, R$. rattus $=1.55 \pm 0.059)$ and a weaker overall effect of age with hosts combined (main effect of age, $F_{2,473}=3.58, P=0.029$, mean helminth species richness in age classes $1-3,=1.12 \pm 0.103$, $1.52 \pm 0.078,1.46 \pm 0.072$, respectively). Not surprisingly, there was a significant difference between the rat species in their mean helminth species richness values from the two sites (2-way interaction host"site, $F_{1,473}=4.62, P=$ 0.032 , Table 5 ). In $R$. norvegicus the values were very similar in both sites but they were significantly higher in $R$. rattus at Chow Kit.

\section{Measure of infracommunity diversity}

The maximum number of helminth species ranged from 5 in $R$. rattus at Chow Kit to 3 in $R$. rattus at Bangsar and in $R$. norvegicus at both sites (Table 5).

The analysis of Brillouin's index of diversity was complicated because parametric models did not converge. Therefore we used non-parametric tests to evaluate the effects of each of the factors in turn. All significant differences were clearly driven by values derived from $R$. rattus, since analyses that were confined to $R$. norvegicus did not reveal significant differences between levels within the specified factors. There was a highly significant difference between the host species (Mann-Whitney $U$ test, $z=-3.46, P=$ $0.001)$ with the mean value of Brillouin's being higher in $R$. rattus $(0.23 \pm 0.015)$ compared with $R$. norvegicus $(0.15$ \pm 0.021 ). The mean value was highest in $R$. rattus from Chow Kit, because at Bangsar, the mean Brillouin's for $R$. rattus was much the same as for $R$. norvegicus at both sites (Table 5). The mean Brillouin's index increased significantly in $R$. rattus with each successive cycle (KruskalWallis test $\left.\chi_{2}^{2}=25.1, P<0.001\right)$ but remained fairly stable in $R$. norvegicus $\left(\chi_{2}^{2}=1.2, P=\mathrm{NS}\right.$; Figure 3a). Moreover, it was higher in age class 2 and 3 animals (Kruskal-Wallis test $\chi_{2}^{2}=6.4, P=0.041$; Figure $3 \mathrm{~b}$ ), compared with age class 1 in $R$. rattus, but showed no significant difference $\left(\chi_{2}^{2}=1.7, P=\mathrm{NS}\right)$ between age classes in $R$. norvegicus. However, the pattern in $R$. rattus was predominantly that observed at Chow Kit (Figure 3c). At Bangsar, the Brillouin's index of diversity in $R$. rattus was still low in age class 2 rats, but increased in age class 3 rats to about the same value as in rats ( $R$. rattus) from Chow Kit.

\section{Prevalence of infection with individual helminth species}

Hymenolepis diminuta This species was the most frequently occurring helminth with an overall prevalence of 36.1\% [CL: 32.7-41.4]. Prevalence was similar in $R$. rattus in both sites and in $R$. norvegicus at Chow Kit, but almost twice as high at Bangsar in $R$. norvegicus (Table 3; for host" site" presence/absence of $H$. diminuta interaction, $\left.\chi_{1}^{2}=6.5, P=0.01\right)$. This higher prevalence in $R$. norvegicus at Bangsar compared with Chow Kit was evident in all three seasonal cycles (Figure 4A).

In the second phase of analysis we fitted models for each host species in turn. In both cases there was a significant seasonal cycle * season * presence/absence of $H$. diminuta interaction (For $R$. norvegicus $\chi_{2}^{2}=7.5, P=0.024$, $R$. rattus $\left.\chi_{2}^{2}=7.43, P=0.024\right)$. Prevalence was high in both rat species in the dry season of seasonal cycle 1 , and then declined in the wet season, but thereafter prevalence values increased consistently with each successive season in $R$. norvegicus, whilst fluctuating at a lower level in $R$. rattus (data not illustrated).

In $R$. norvegicus, the age related prevalence of $H$. diminuta varied between both sites and seasons (analysis restricted to $R$. norvegicus, season"site*age*presence/absence $H$. diminuta, $\chi_{2}^{2}=6.3, P=0.042$ ). In the dry season at both sites there was a pattern of increasing prevalence with age, but in the wet season at Chow Kit prevalence declined with age and at Bangsar prevalence peaked in mature and not the oldest rats (Figure 4B).

For $R$. rattus the second significant term incorporating the presence/absence of $H$. diminuta was the seasonal cycle ${ }^{*}$ site ${ }^{*}$ presence/absence interaction $\left(\chi_{2}^{2}=8.4, P=\right.$ $0.015)$. This arose because at Chow Kit prevalence was consistent across the 3 seasonal cycles, but fell from $48 \%$ to zero at Bangsar (Figure $4 \mathrm{C}$ ). 

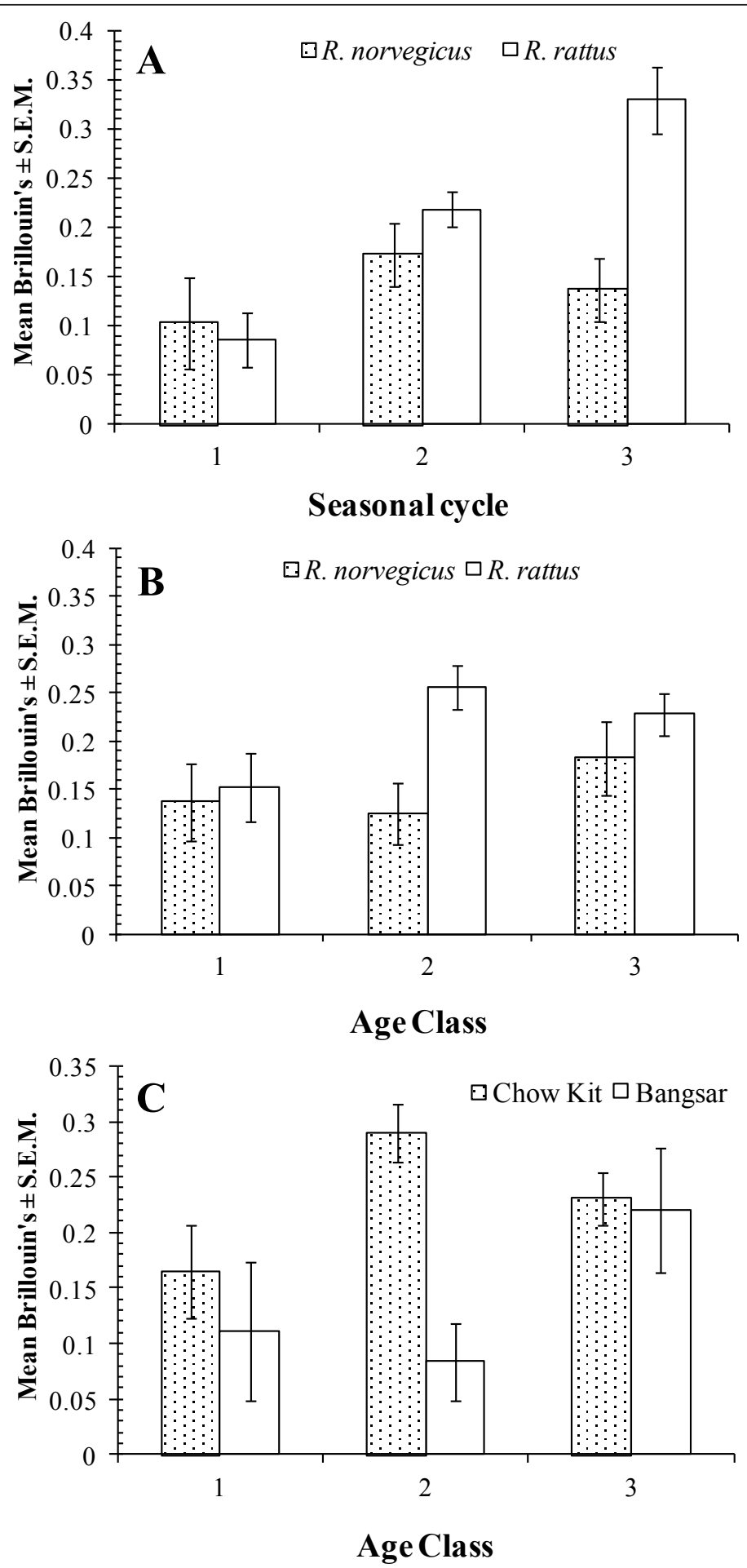

Figure 3 Factors affecting Brillouin's index of helminth diversity in each rat species. The effects of seasonal cycle (A), age class(B) in both host species and age class in $R$. rattus by site (C).

The final interaction involving $H$. diminuta in $R$. rattus was site"age*"presence/absence $\left(\chi_{2}^{2}=7.0, P=0.030\right)$. At Chow Kit all three age classes of $R$. rattus showed similar prevalences whereas at Bangsar prevalence increased markedly from juveniles to the oldest individuals (Figure 4D).

Heterakis spumosum This was the second most frequently occurring helminth with a prevalence of $29.9 \%$ 

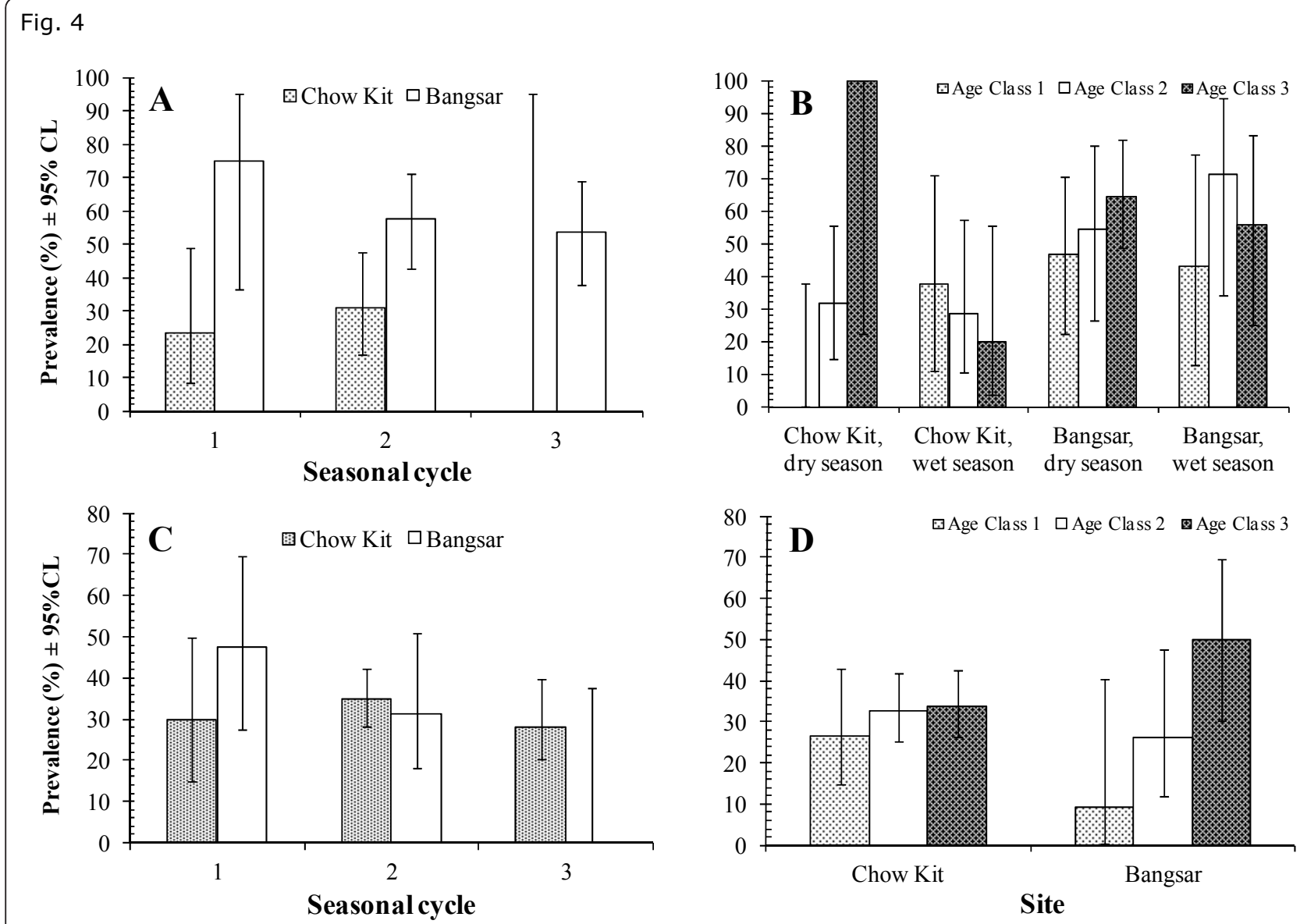

Figure 4 Factors affecting prevalence of Hymenolepis diminuta. Variation between the two sites and across 3 seasonal cycles in R. norvegicus (A), in prevalence in the 3 age classes, two sites and two seasons, in R. norvegicus (B), in prevalence across the three seasonal cycles and in both sites in R.rattus (C) and in prevalence between age classes in both sites in $R$. rattus (D). See text for statistical significance of individual factors and interactions; for the fit of the overall minimal sufficient model incorporating both hosts $\chi^{2}{ }_{183}=93.8, P=1.0$; for that restricted to $R$. norvegicus $\chi_{103}^{2}=70.9, P=0.99$, and for that restricted to $R$. rattus $\chi_{108}^{2}=66.6, P=0.99$.

[CL:26.0-34.2]. With the exception of $R$. rattus at Chow Kit, prevalence was remarkably uniform in $R$. norvegicus in both sites and in $R$. rattus at Bangsar but twice as high at Chow Kit in $R$. rattus (Table 3). Nevertheless, with both hosts combined there was a highly significant difference in the prevalence of $H$. spumosum between sites (analysis incorporating both rat species, site"presence/absence of $H$. spumosum, $\chi^{2}{ }_{1}=8.1, P=0.005$; at Chow Kit prevalence was 34.4\% (CL: 29.19-39.99\%) and at Bangsar 18.6\% (CL:12.95-25.79\%)).

Although the overall prevalence was higher in $R$. rattus (34.5\%) compared with $R$. norvegicus (18.6\%), this difference was confounded by some interactions with age and season. In the dry season the prevalence was higher in all age classes in $R$. rattus, whereas prevalence in $R$. norvegicus was higher in age class 3 in the wet season (season*age"host"presence/absence of $H$. spumosum, $\chi^{2}{ }_{2}=10.0, P$ $=0.007)$. When the effect of season was collapsed, the difference between age classes was far more pronounced in $R$. norvegicus (prevalence for age class 1 to $3=8.1 \%$, $11.8 \%$ and $32.7 \%$, respectively) compared with $R$. rattus (30.6\%, 31.7\% and 38.3\%, respectively). Prevalence in both hosts declined in the wet season in seasonal cycle 1 , and this drop was still evident in the dry season of seasonal cycle 2 . Prevalence values then recovered in both hosts but dropped again in $R$. rattus during the wet season at the end of seasonal cycle 3 (season"cycle"host species* presence/absence of $H$. spumosum, $\chi_{2}^{2}=9.1, P=$ 0.011, Data not illustrated).

Hymenolepis nana This was the third most frequently occurring species with an overall prevalence of $28.2 \%$ [CL:25.1-33.2]), and prevalence was higher in $R$. rattus (31.0\%, [CL:27.3-37.1]) compared with $R$. norvegicus (21.4\%, [CL:15.9-29.6]). This difference between hosts was consistent in both sites (Table 3), but was not found to be significant because prevalence was confounded by combinations of the other factors in the analysis. A model that included host species as a factor comprised 
13 terms of which six 4-way interactions included presence/absence of $H$. nana together with various combinations of site, age, season and cycle. Sex did not play a role in determining the prevalence of $H$. nana (host species combined, males $=30.5 \%$ [CL:25.3-37.3]; females $26.4 \%$ [CL:22.0-32.6]).

In $R$. norvegicus prevalence varied across the three age classes and across the three seasonal cycles (age* season*cycle ${ }^{*}$ presence/absence of $H$. nana, $\left.\chi^{2}{ }_{4}=9.5, P=0.05\right)$. In the dry season prevalence was low in all three cycles in age class 3 rats and in the wet season it was higher in each case. In $R$. rattus, the only interaction involving the presence/absence of $H$. nana was one incorporating site and season in relation to age (site* season*age* presence/ absence of $H$. nana, $\left.\chi_{2}^{2}=15.6, P=0.0004\right)$. There was little difference in prevalence between age classes 1 and 2 , but in three data subsets the prevalence was lower in the age class 3 rats (Chow Kit dry and wet season and Bangsar in the wet season), the exception being Bangsar in the dry season.

Mastophorus muris This nematode was present in 17.7\% [CL:13.0-23.6] of rats, and almost twice as frequently encountered in $R$. rattus (20.3\% [CL:16.0-25.2]) compared with $R$. norvegicus (11.4\% [CL:7.0-17.7]).

The overall prevalence was up to 5 times higher at Chow Kit compared to Bangsar, and the higher prevalence at Chow Kit was common to both rat species (Table 3). Prevalence was also higher in females $(21.5 \%$ [CL:17.6-25.9]) compared with males (13.2\% [CL:10.316.7]) but not significant because of the confounding influences of more complex interactions with site, season and host. When the analysis was confined to $R$. norvegicus, only one of the 4 interactions included the presence/absence of $M$. muris (site ${ }^{*}$ sex $^{*}$ age e $^{*}$ presence/ absence of $M$. muris, $\chi_{2}^{2}=7.5, P=0.024$ ) but no clear patterns were evident.

Analysis of $R$. rattus, however, revealed a very distinct picture with six interaction terms, four of which were 2 way interactions. There was a marked age effect (age*presence/absence of $M$. muris, $\chi_{2}^{2}=13.7, P=0.0013$ ) with an increasing prevalence of infection with age (Figure $5 \mathrm{~A}$ ). Prevalence varied significantly between sites (site* presence/absence of $M$. muris, $\chi^{2}{ }_{1}=5.4, P=0.02$ ), being higher at Chow Kit as shown in Table 3, and between seasonal cycles, being highest in season cycle $2(24.5 \%$, [CL:20.9-28.6]), compared with cycle 1 (8.3\% [CL:1.324.1]) and cycle 3 (16.9\% [CL:8.8-28.8]; $\chi_{2}^{2}=7.8, P=$ $0.02)$. Finally, prevalence was also significantly higher in the wet compared with dry season $\left(\chi^{2}{ }_{1}=4.0, P=0.044\right.$; wet season $=23.4 \%$ [CL:16.7-31.4]; dry season $=17.8 \%$ [CL:11.3-26.4]). The increase from dry to wet season is apparent in each seasonal cycle, despite the differences in prevalence between cycles (Figure 5B).
Nippostrongylus brasiliensis Nippostrongylus brasiliensis had an overall prevalence of 16.5\% (95\% [CL: 11.822.3]. Prevalence was higher in $R$. rattus compared to $R$. norvegicus, being 18.8\% [CL:14.7-23.7] and 10.7\% [CL:6.4-17.0] respectively, but with hosts combined prevalence values were similar at both sites (Chow Kit = 16.8\% [CL:12.9-21.5]; Bangsar $=15.7 \%$ [CL:10.5-22.5]). However, when broken down by host and site (Table 3), prevalence can be seen to have been particularly low in $R$. norvegicus at Chow Kit. Statistically the difference between hosts was confounded additionally by season (model incorporating both hosts, host ${ }^{*}$ site*season* presence/absence of $N$. brasiliensis $\chi^{2}{ }_{1}=7.7, P=0.0056$ and model restricted to $R$. norvegicus, site*season*presence/absence of $N$. brasiliensis, $\left.\chi^{2}{ }_{1}=4.7, P=0.03\right)$. Prevalence was higher in $R$. rattus (relative to $R$. norvegicus) in Chow Kit and at Bangsar in the dry seasons, but not in the wet season at Bangsar, when prevalence among $R$. norvegicus exceeded 40\% (Data not shown).

Statistical analysis revealed that the strongest effect was that arising from differences in prevalence between the seasonal cycles. This was evident in both hosts (cycle ${ }^{*}$ presence/absence of $N$. brasiliensis, $\chi_{2}^{2}=23.2$, $P<0.0001)$, in only $R$. rattus $\left(\chi_{2}^{2}=18.1, P<0.0001\right)$, but not when $R$. norvegicus were analyzed alone. This seasonal cycle effect is shown for both species separately in Figure 6A. In both, prevalence increased with successive seasonal cycles, but the increase was more marked in $R$. rattus, $R$. norvegicus following a similar pattern but more slowly. When the season effect was added to that of seasonal cycles, an increasing prevalence in $R$. rattus was shown starting from the dry season of cycle 1 through to the dry season of cycle 3 , and a similar but delayed pattern of change in $R$. norvegicus with a low in the dry season of cycle 2 (Figure 6B).

\section{Measures of dispersion}

The majority of helminths in the two rat species from both sites showed overdispersed (aggregated) distributions where $D$ exceeded 0.7 and was generally much higher, and $I$ exceeded 1 in all cases ranging from 3 to 146.8 . The negative binomial constants $k$, were in general consistent with a negative binomial distribution. In 18 of the 30 subsets of data the distributions were not significantly different from those predicted by the negative binomial distribution and in 5 cases it was not possible to test for goodness of fit.

\section{Abundance of infection with helminth species}

The mean helminth burdens (all species combined) varied significantly between hosts (Table $5 ; \chi^{2}{ }_{1}=13.2, P=$ 0.0003 ), being almost twice as high in $R$. rattus ( $R$. norvegicus $=17.7 \pm 3.39 ;$. rattus $=32.7 \pm 3.68)$, but not between sites, although arithmetically mean total helminth burdens were higher at Chow Kit (host species 

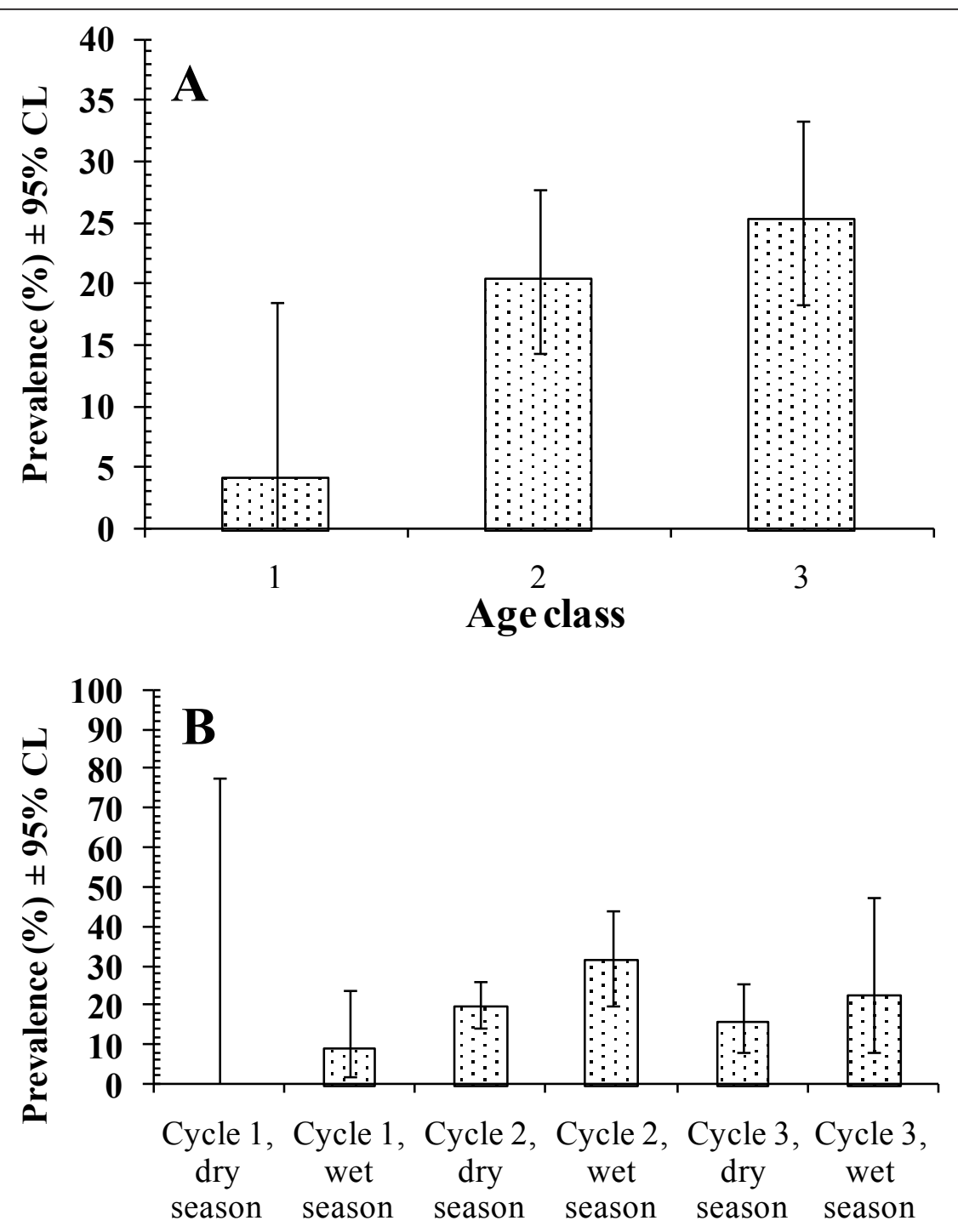

\section{Cycle and season}

Figure 5 Factors affecting the prevalence of Mastophorus muris in R. rattus. Effect of host age (A) and seasonal cycles (B). The overall model fit of the minimum sufficient model confined to $R$. rattus was $\chi_{121}^{2}=76.8, P=0.99$. See text for significance of individual factors and their interactions.

combined, Chow Kit $=30.6 \pm 3.61$; Bangsar $=22.9 \pm$ 2.85). Nevertheless, there was also a significant difference between sites in $R$. norvegicus when the analysis was restricted to this species (Table $5 ; \chi^{2}{ }_{1}=9.13, P=0.0025$ ).

The strongest influences on total helminth burden were season $\left(\chi^{2}{ }_{1}=24.8, P<0.0001\right)$ and seasonal cycle $\left(\chi_{2}^{2}=13.9, P=0.0009\right)$, and the marked increase in helminth burdens from the dry to the following wet season was evident in both species (Figure 7A; for $R$. norvegicus $\chi_{1}^{2}=20.4, P<0.0001$; for $R$. rattus $\chi_{1}^{2}=8.2, P=0.0043$ ), except for $R$. rattus in cycle 3 . There was also a steady increase in total helminth burdens with each successive seasonal cycle (hosts and sites combined, values for seasonal cycles $1,2 \& 3$, were: $24.7 \pm 5.74,25.5 \pm 3.38$ and $36.7 \pm 6.75$, respectively).

There was a pronounced effect of host $\operatorname{sex}\left(\chi^{2}{ }_{1}=15.4\right.$, $P=0.0001)$, with male rats harbouring on average more worms than females (males $=34.9 \pm 5.13$; females $=22.9 \pm$ 2.85). This effect of host sex was in the same direction in both rat hosts $(R$. norvegicus males $=23.0 \pm 5.99$, females $=11.9 \pm 2.44 ; R$. rattus males $=41.0 \pm 7.07$, females $26.6 \pm$ 3.68) but, with other factors taken into account, was only significant in $R$. rattus $\left(\chi^{2}{ }_{1}=9.15, P=0.0025\right)$

A highly significant 2-way interaction was found between host age and seasonal cycle on helminth abundance $\left(\chi^{2}{ }_{4}=22.1, P=0.0002\right)$. As mean helminth 

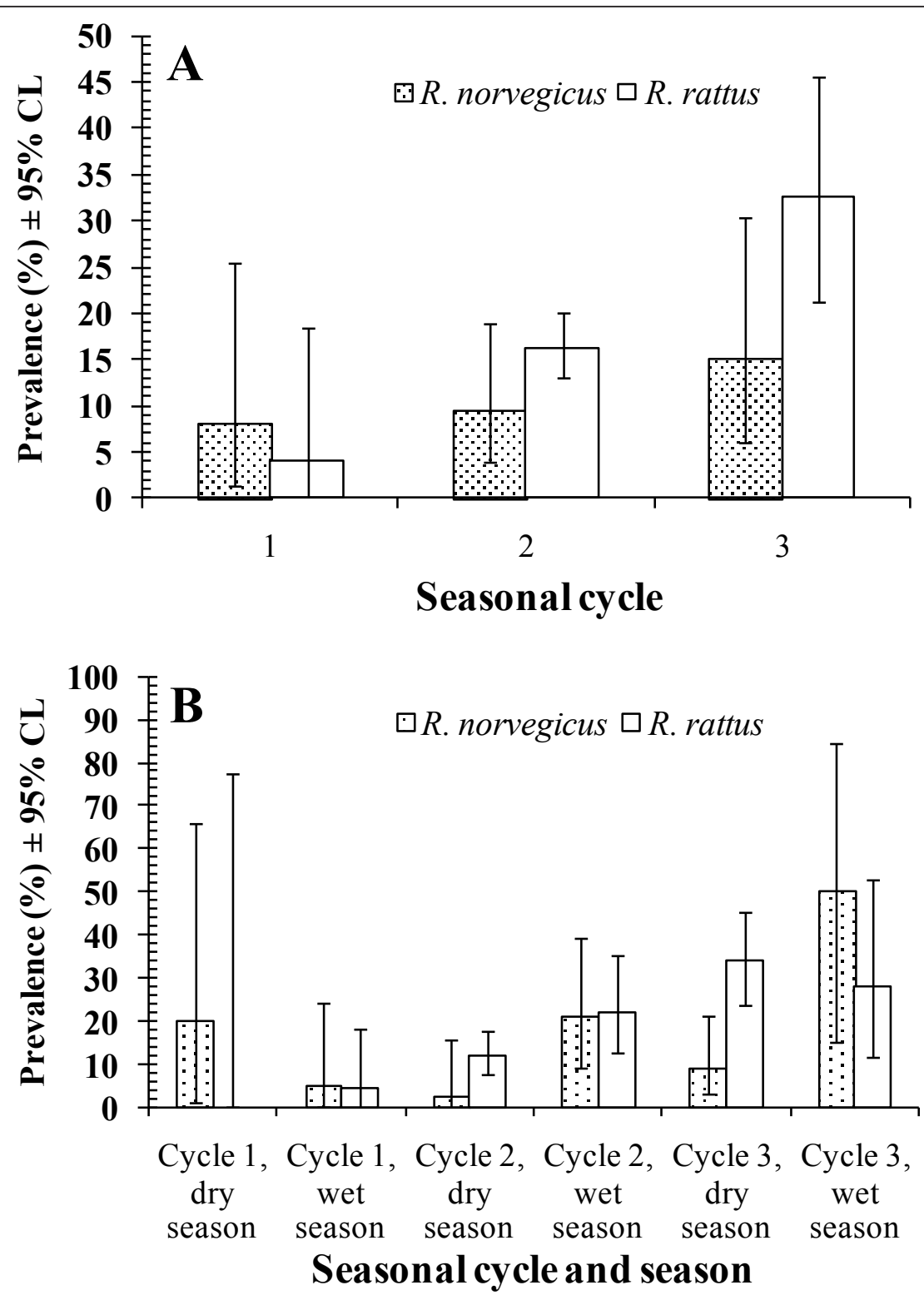

Figure 6 Factors affecting variation in the prevalence of Nippostrongylus brasiliensis. The effect of 3 seasonal cycles (A) and seasonal cycles combined with both seasons in each cycle (B). The overall model fit of the minimum sufficient model incorporating both hosts was $\chi^{2} 213$ $=113.9, P=1.0$, confined to $R$. norvegicus $\chi_{100}^{2}=43.4, P=1.0$ and confined to $R$. rattus $\chi^{2}{ }_{108}=81.7, P=0.97$. See text for significance of individual factors and their interactions.

burdens accumulated with increasing age in both hosts in seasonal cycles 2 and 3, but not in seasonal cycle 1 when worm burdens clearly fell with increasing age (Figure 7B).

Hymenolepis diminuta There was no significant difference in the overall abundance of $H$. diminuta between sites (hosts combined, Chow Kit $=2.7 \pm 0.65$; Bangsar $=$ $3.6 \pm 0.63$ ) nor between hosts (sites combined, $R$. norvegicus $=3.2 \pm 0.61 ; R$. rattus $=2.9 \pm 0.66)$, when other factors were taken into account. However, in $R$. norvegicus abundance was significantly higher at Bangsar (Table 6; $\left.\chi_{1}^{2}=7.20, P=0.0007\right)$.

In $R$. rattus abundance of $H$. diminuta clearly declined significantly across the 3 seasonal cycles $\left(\chi^{2}{ }_{2}=11.26, P=\right.$ $0.0036)$, whilst in $R$. norvegicus abundance was relatively stable (Figure 8A). There was no significant effect of age in either host, but there was a sex effect in $R$. rattus $\left(\chi^{2}{ }_{1}=\right.$ 7.4, $P=0.0064)$, with females harbouring more worms than males $(R$. rattus, males $1.6 \pm 0.29$, females $=3.8 \pm$ 1.11). In $R$. norvegicus abundance of $H$. diminuta was in 


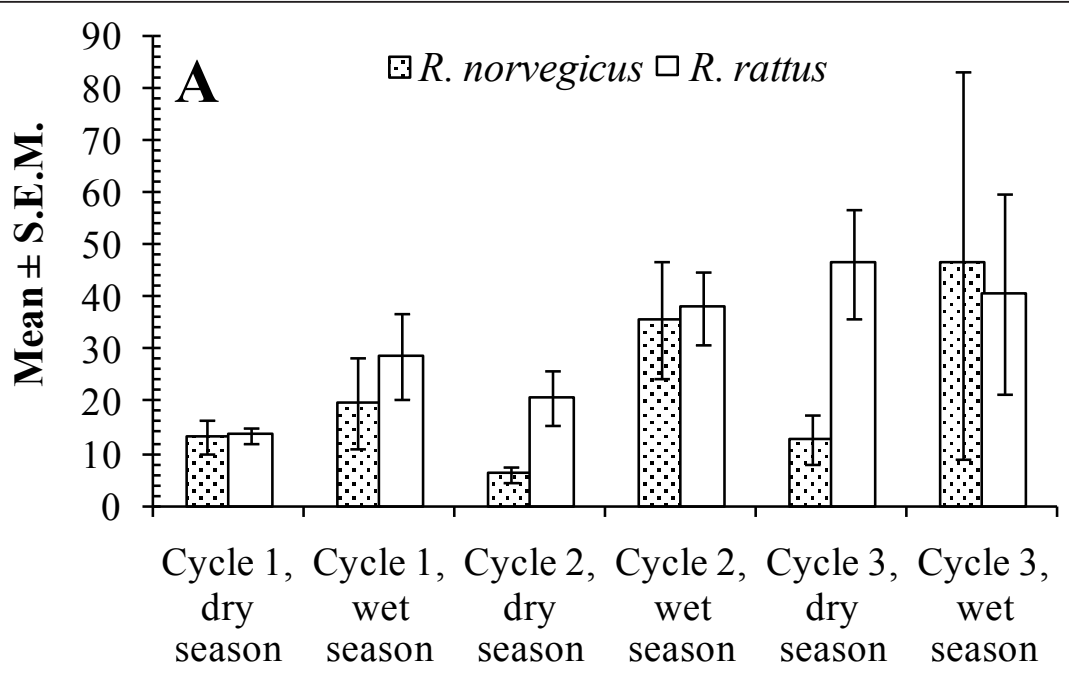

\section{Seasonal cycle \& season}

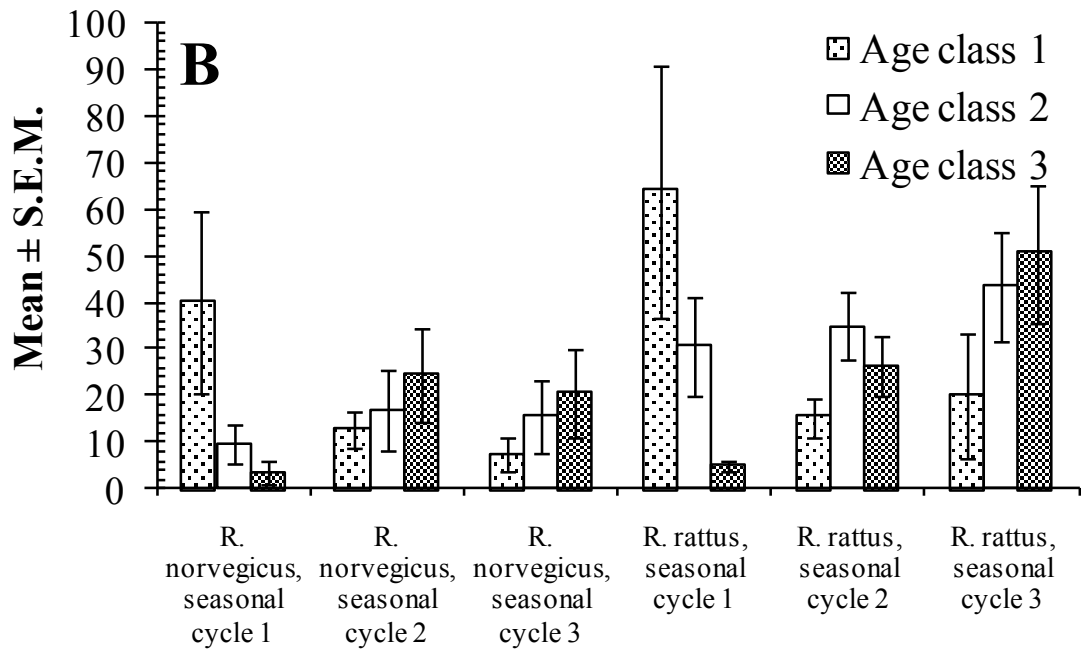

\section{Host species and seasonal cycle}

Figure 7 Factors affecting the abundance of helminth species in both rat host species. The effect of seasonal cycles and successive seasons on total helminth burdens (A) and variation in total helminth burden between age classes across 3 seasonal cycles (B). See text for statistical analysis.

the opposite direction but this was not significant when other factors were taken into consideration (males $=3.9 \pm$ 1.02 , females $=2.5 \pm 0.61$ )

Heterakis spumosum There was no significant difference in the overall abundance of $H$. spumosum between sites (hosts combined, Chow Kit $=2.0 \pm 0.29$; Bangsar $=$ $0.8 \pm 0.18$ ) nor between hosts (sites combined, $R$. norvegicus $=1.2 \pm 0.40 ; R$. rattus $=1.8 \pm 0.25)$. However, abundance of this nematode varied significantly between sites in $R$. rattus (higher at Chow Kit; $\chi^{2}{ }_{1}=5.54, P=0.019$ but not in $R$. norvegicus (Table 6), although the difference between sites was in the same direction. There was no significant difference in abundance of $H$. spumosum between seasonal cycles in $R$. norvegicus, but in $R$. rattus abundance clearly increased significantly with each successive seasonal cycle (Figure $8 \mathrm{~B} ; \chi^{2}{ }_{2}=8.27, P=0.016$ ).

Hymenolepis nana This cestode was considerably more abundant in $R$. rattus $(14.2 \pm 2.13)$ compared with $R$. norvegicus $\left(4.8 \pm 1.51 ; \chi^{2}{ }_{1}=11.82, P=0.0006\right)$ and this pattern was consistent across both sites (Table 6). It was also a species that clearly increased in abundance in the wet season (with hosts combined $\chi^{2}{ }_{1}=8.69, P=$ 0.0032 ). This cycle of abundance was apparent in all three seasonal cycles in $R$. rattus $\left(\chi^{2}{ }_{1}=4.83, P=0.028\right)$ 
Table 6 Abundance of helminth tax by host species and site

\begin{tabular}{|c|c|c|c|c|c|c|}
\hline \multirow[b]{3}{*}{ Taxon } & \multirow[b]{3}{*}{ Species } & \multicolumn{4}{|l|}{ Species } & \multirow[b]{3}{*}{ Combined } \\
\hline & & \multicolumn{2}{|c|}{ R. norvegicus } & \multicolumn{2}{|l|}{ R. rattus } & \\
\hline & & Chow Kit & Bangsar & Chow Kit & Bangsar & \\
\hline \multirow[t]{7}{*}{ Nematodes } & Mastophorus muris & $1.0 \pm 0.36$ & $0.2 \pm 0.15$ & $1.2 \pm 0.18$ & $0.2 \pm 0.12$ & $0.9 \pm 0.12$ \\
\hline & Syphacia muris & 0 & 0 & $5.7 \pm 2.83$ & 0 & $3.4 \pm 1.66$ \\
\hline & Nippostrongylus brasiliensis & $0.05 \pm 0.05$ & $12.4 \pm 4.77$ & $8.6 \pm 1.80$ & $1.4 \pm 0.64$ & $7.3 \pm 1.33$ \\
\hline & Gongylonema neoplasticum & 0 & 0 & $0.007 \pm 0.005$ & 0 & $0.004 \pm 0.005$ \\
\hline & Pterygodermatites whartoni/tani & $0.05 \pm 0.05$ & $1.1 \pm 0.82$ & $0.4 \pm 0.17$ & $0.5 \pm 0.35$ & $0.5 \pm 0.18$ \\
\hline & Heterakis spumosum & $1.6 \pm 0.88$ & $0.9 \pm 0.25$ & $2.0 \pm 0.30$ & $0.7 \pm 0.27$ & $1.6 \pm 0.21$ \\
\hline & Angiostrongylus malaysiensis & $0.03 \pm 0.03$ & $0.01 \pm 0.01$ & $0.04 \pm 0.03$ & 0 & $0.03 \pm 0.02$ \\
\hline \multicolumn{2}{|c|}{ All nematodes } & $2.7 \pm 0.96$ & $14.6 \pm 4.83$ & $17.9 \pm 3.46$ & $2.8 \pm 0.75$ & $13.6 \pm 2.20$ \\
\hline \multirow[t]{3}{*}{ Cestodes } & Hymenolepis diminuta & $1.9 \pm 0.65$ & $4.2 \pm 0.94$ & $2.9 \pm 0.78$ & $2.7 \pm 0.75$ & $3.0 \pm 0.50$ \\
\hline & Hymenolepis nana & $4.9 \pm 2.10$ & $4.7 \pm 2.12$ & $14.0 \pm 2.36$ & $15.1 \pm 5.02$ & $11.5 \pm 1.59$ \\
\hline & Taenia taeniaeformis & 0 & 0 & $0.02 \pm 0.01$ & 0 & $0.01 \pm 0.005$ \\
\hline \multicolumn{2}{|c|}{ All adult cestodes } & $6.8 \pm 2.14$ & $9.0 \pm 2.22$ & $16.9 \pm 2.44$ & $17.8 \pm 4.94$ & $14.4 \pm 1.63$ \\
\hline \multicolumn{2}{|c|}{ All cestodes } & $6.8 \pm 2.14$ & $9.0 \pm 2.22$ & $16.9 \pm 2.44$ & $17.8 \pm 4.94$ & $14.4 \pm 1.63$ \\
\hline Acanthocep & Moniliformis moniliformis & $0.3 \pm 0.14$ & $0.2 \pm 0.08$ & $0.2 \pm 0.04$ & $1.0 \pm 0.80$ & $0.3 \pm 0.11$ \\
\hline \multicolumn{2}{|c|}{ All helminths } & $9.8 \pm 2.29$ & $23.7 \pm 5.60$ & $35.0 \pm 4.30$ & $21.6 \pm 5.37$ & $28.4 \pm 2.81$ \\
\hline
\end{tabular}

with a similar pattern in cycles 1 and 2 in $R$. norvegicus but not in seasonal cycle 3 (Figure $8 \mathrm{C}$ ).

The age effect was highly significant when both hosts were combined $\left(\chi_{2}^{2}=10.22, P=0.006\right)$, with declining abundance of $H$. nana as age increased. Models for $R$. norvegicus alone did not converge but analysis by non-parametric tests confirmed a significant difference between groups (Kruskal-Wallis test, $\chi_{2}^{2}=7.8, P=0.02$; Figure 9A). Age did not appear in the minimum sufficient model for $R$. rattus, but as with $R$. norvegicus there was a significant difference between groups when tested non-parametrically (Figure 9A; Kruskal-Wallis test, $\chi^{2}{ }_{2}=11.3, P=$ 0.003).

Mastophorus muris This species was significantly more abundant at Chow Kit (hosts combined, $1.1 \pm 0.16$ ) compared with Bangsar $\left(0.2 \pm 0.10 ; \chi^{2}{ }_{1}=15.32, P=0.0001\right)$, and this difference between sites was consistent in both hosts (Table 6). Analysis by GLM for $R$. rattus gave $\chi^{2}{ }_{1}=$ 9.36, $P=0.002$ and by non-parametric tests confirmed that there was also a significant difference between sites in $R$. norvegicus (Mann-Whitney $\mathrm{U}$ test, $Z=-3.3, \mathrm{P}=0.001$ ).

Overall, abundance of $M$. muris was higher in $R$. rattus ( $R$. rattus $=1.0 \pm 0.15, R$. norvegicus $=0.5 \pm 0.18$ ), but this did not emerge as a significant effect in GLM, although without other factors being taken into account there was a significant difference by non-parametric analysis (MannWhitney $U$ test $Z=-2.36, P=0.018$ ).

There was an overall effect of host age $\left(\chi_{2}^{2}=12.4, P=\right.$ $0.002)$ and the trend of increasing abundance with increasing age was consistent in both hosts, although only significant in $R$. rattus (Figure 9B; $\chi_{2}^{2}=14.4, P=0.0008$ ).

$M$. muris also showed significantly higher abundance in females $(1.1 \pm 0.18)$ compared with males $(0.6 \pm 0.14)$ when hosts were combined $\left(\chi^{2}{ }_{1}=6.23, P=0.013\right)$. Although sex did not emerge as a main effect in the GLM restricted to $R$. rattus, the non-parametric test indicated that as in the entire data-set a sex bias was apparent $(R$. rattus, males $=0.7 \pm 0.18$, females $=1.2 \pm$ 0.22 , Mann-Whitney $U$ test $Z=-2.2-4, P=0.028)$. In $R$. norvegicus the mean was higher among females also, but not significantly so (females $=0.6 \pm 0.31$, males $=$ $0.4 \pm 0.20)$.

There was a significant difference in abundance between seasons (mean in wet season $=1.1 \pm 0.21$, and in the dry season $0.6 \pm 0.13, \chi^{2}{ }_{1}=6.23, P=0.013$ ) when hosts were combined and this was also significant in $R$. norvegicus in which abundance was five times higher in the wet season (mean for wet season $=1.0 \pm 0.43$, dry season $0.2 \pm 0.09$, $\chi_{1}^{2}=5.37, P=0.021$ ) but not in $R$. rattus (mean for wet season $=1.2 \pm 0.24$, dry season $0.8 \pm 0.19$ )

Nippostrongylus brasiliensis There was no difference in abundance of $N$. brasiliensis between the hosts ( $R$. norvegicus $=7.1 \pm 2.77 ; R$. rattus $=7.4 \pm 1.50)$, nor between the sites when hosts were pooled (Chow Kit = $7.1 \pm 1.50$; Bangsar = $7.7 \pm 2.77$ ). However, this species was clearly more abundant in $R$. norvegicus at Bangsar and in $R$. rattus at Chow Kit, and this interaction was borne out by the statistical analysis (Table 6; 2 -way interaction site ${ }^{*}$ host species $\left.\chi^{2}{ }_{1}=18.81, P<0.0001\right)$. No other factors or 2-way combinations were significant. However, changes in abundance of $N$. brasiliensis occurred across the seasonsal cycle and in successive seasons (Figure 9C). These data show a tendency to increasing abundance with successive cycles, particularly in $R$. norvegicus in the wet season, and an increase in abundance in $R$. rattus between seasonal cycles 1 and 3 . 

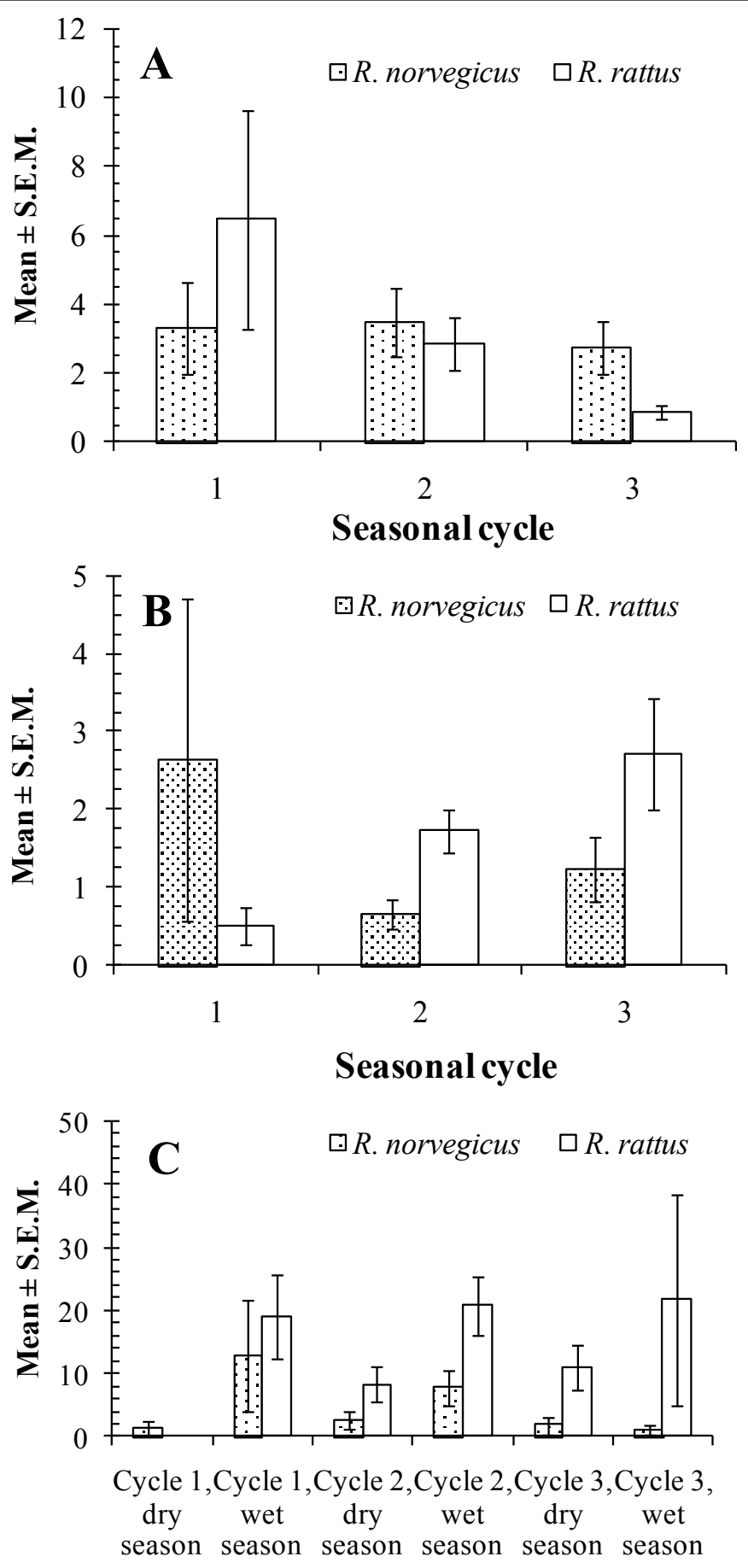

\section{Seasonal cycle and season}

Figure 8 Factors affecting the abundance of $\boldsymbol{H}$. diminuta, $\boldsymbol{H}$. spumosum and $\boldsymbol{H}$. nana in both rat species. The effect of seasonal cycles on the abundance of $H$. diminuta (A), H. spumosum (B) and also successive seasons and seasonal cycles on the abundance of $H$. nana (C). See text for statistical analysis.

Although, not independently significant, there was also a trend of increasing abundance with age in $R$. norvegicus $($ means $=1.5 \pm 0.79,4.4 \pm 3.95$ and $13.8 \pm 6.28$ for age classes 1-3, respectively) and a peak in age class 2 with subsequent decline in $R$. rattus (means $=1.2 \pm 0.98$, $10.5 \pm 3.08$ and $6.5 \pm 1.74$, respectively). Moreover, 


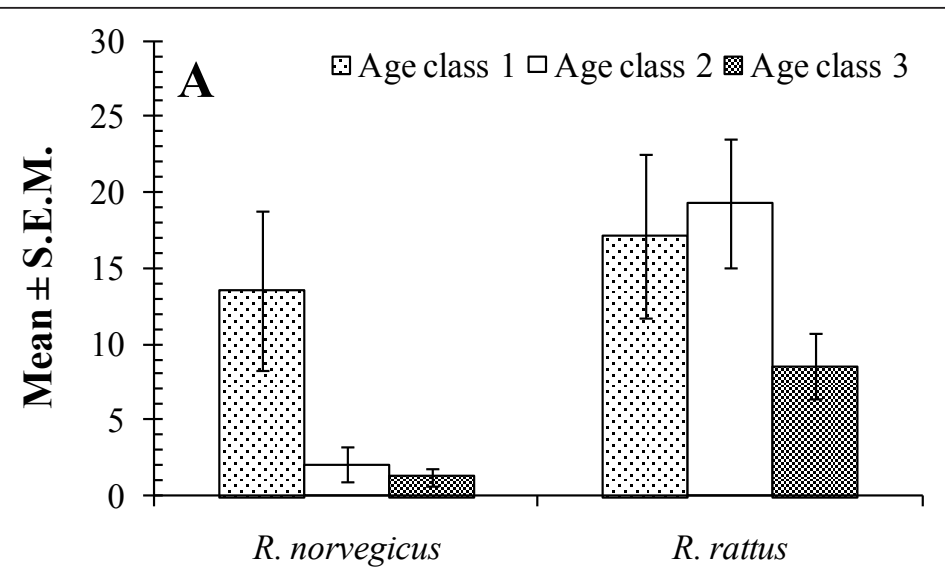

\section{Host species}
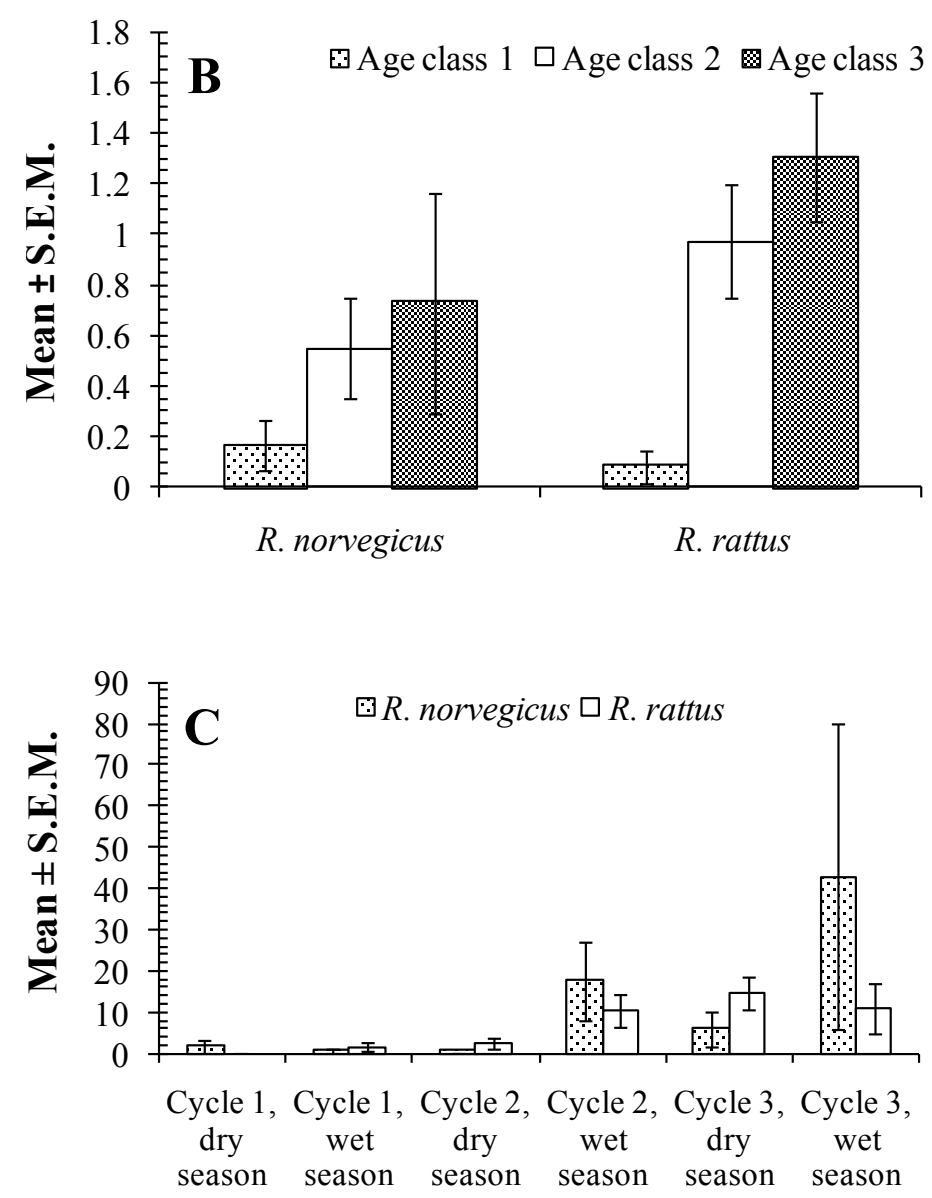

\section{Seasonal cycle and season}

Figure 9 Factors affecting the abundance of $\boldsymbol{H}$. nana, $\boldsymbol{M}$. muris and $\boldsymbol{N}$. brasiliensis. The effect of host age on $\boldsymbol{H}$. nana (A) and $\boldsymbol{M}$. muris (B), and that of successive seasons in seasonal cycles on the abundance of $N$. brasiliensis (C) in each of the host species. See text for statistical analysis.

there was also an overall bias in the direction of male rats in both species $($ mean $=11.5 \pm 5.03,2.2 \pm 1.49$ for male and female $R$. norvegicus, and $10.0 \pm 2.37,5.5 \pm$
1.92 for male and female $R$. rattus, respectively), but this was not significant when other factors were included in the model. 


\section{Discussion}

Despite their importance as reservoirs of zoonotic infections, wild rats have seldom been studied thoroughly with respect to the epidemiology of their helminths, and we are not aware of any other studies in which the helminth communities of the two common commensal rat species have been compared directly by rigorous analysis with possible confounding factors taken into account. In comparison with ecological studies of wood mice and bank voles in Europe [7,9-12,35-41], there are few quantitative studies $[8,42]$ of the helminth communities of rats exploring thoroughly a range of factors that have the potential to influence parasite burdens, and then clearly identifying and prioritising them. For the most part the literature on their helminths comprises species descriptions and lists from sites in different countries e.g. in the Middle East [43,44], Korea [45], Nigeria [46] and Malaysia [19-21,26,27]. Comparison of the helminth communities supported by each of these species was therefore one of of our key objectives.

As in many other cities around the globe, in Kuala Lumpur, $R$. rattus and $R$. norvegicus are the two dominant species of rats living commensally with people, but other species are also occasionally reported in Kuala Lumpur and the surrounding region, although seldom in high numbers $[17,21,28]$. The two species are closely related, with similar karyotypes [47] and $R$. norvegicus was formerly classed as a subspecies of $R$. rattus [48]. Both rat species have adapted so successfully to a commensal life style that they are universally regarded as pests. Despite the many diverse methods used to control their populations, both species are widespread globally and both support a rich community of helminths, as the current study has shown (80\% were infected with at least one of the helminths identified here and the mean infracommunity species richness was 1.4), some of which are infectious to humans. In this paper we have focused on $R$. rattus and $R$. norvegicus as the obvious starting point for understanding the role of wild rats in the transmission of helminths within the city.

Our random trapping efforts yielded more than twice as many $R$. rattus compared with $R$. norvegicus, suggesting differences in the population densities of both species. Therefore, not surprisingly, the helminth species list for $R$. rattus was longer than that for $R$. norvegicus, since species richness is dependent on host density and sampling effort [49-51]. Each of the eleven species identified was recorded from $R$. rattus, whereas 3 were absent from $R$. norvegicus (S. muris, G. neoplasticum and T. taeniaeformis) even though each has been reported from this host in other studies [52,53]. In real terms $82 \%$ of the helminths were recovered from $R$. rattus and even when sampling effort was taken into consideration almost $63 \%$ were still from this host species. This bias in favour of $R$. rattus was also reflected at the infracommunity level in significantly higher values for species richness and for abundance of helminths, and for individual species such as H. nana. With all other factors taken into consideration, $R$. rattus carried significantly heavier worm burdens than $R$. norvegicus with mean values almost twice as high. In our study, therefore, and on these criteria, $R$. rattus was a more important reservoir of helminth infections than $R$. norvegicus.

We chose two quite different sites to trap rats in Kuala Lumpur. Chow Kit is the largest wet market in the city, so rats living in the site will have benefited from plentiful resources, and this site yielded most of the animals for the current project. In fact $59 \%$ of all the animals sampled were $R$. rattus trapped at this market location, so assuming that these figures reflect the overall population density, $R$. rattus clearly does well in Chow Kit and the life cycles and transmission routes of their helminths will have been well entrenched in the site. By comparison, few $R$. norvegicus were caught in Chow Kit (only $12.3 \%$ of all rats), and these accounted for only $10.9 \%$ of the helminths recovered. The smaller numbers of $R$. norvegicus here may be linked to differences in the habitat preferences of both rat species. It has been reported that $R$. norvegicus tends to favour residential sites [48], e.g. Bangsar, by occupying wall cavities and panelling of buildings, whereas $R$. rattus is typically associated with refuse and garbage tips and stores, as well as with cooked foodstuff, all readily available in the wet market of Chow Kit. Thus whereas $R$. rattus trapped at Chow Kit harboured the greatest percentage of helminths (38.9\%) and showed the highest mean infracommunity species richness, $R$. norvegicus at Chow Kit had the fewest helminths and had the lowest mean species richness. Since the two rat species shared eight of the eleven species of helminths recorded in this study, it would appear that the infective stages, particularly those of the monoxenous nematodes, released from $R$. rattus, are not well transmitted to $R$. norvegicus at this site. This suggests that at least to some extent the two rats occupy different niches at Chow Kit likely to be related to their differing habitat preferences.

In the more affluent sector of the city, at our second site, Bangsar, whilst fewer $R$. rattus were caught, the $R$. norvegicus sample size was larger. Bangsar is considerably cleaner compared to Chow Kit, and garbage here is better managed and disposed of. Interestingly, here the two rat species accounted for very similar percentages of the helminths recovered. Because at Chow Kit $R$. rattus accounted for a large proportion of the helminths and $R$. norvegicus for relatively fewer, when data for the rat species were pooled, and expressed in percentage terms there was no real difference in helminths recovered from each of the two sites. The key difference 
was that in Chow Kit $R$. rattus was clearly more important than $R$. norvegicus as a carrier of helminths. Thus the disparity between the host species was essentially site specific and not equally evident at Bangsar.

Of the eleven species of helminths recorded, none of the nematodes are generally considered to be human infectious, although some authorities consider some to have zoonotic potential [28]. In addition to those we found, rats can be expected to harbour the infective stages of Toxocara cati and T. malaysiensis [54,55], both of which are known to exist in the local cat population (JW Lewis and SN Mohd Zain, unpublished observations), but in the current work the musculature of the rats was not examined in sufficient detail to reveal these parasites. There was no evidence in the current study of Calodium hepaticum (previously known as Capillaria hepatica, [56]), in the liver of the rats, although three of 50 rats examined earlier were infected with this parasite and it is known to have potential to cause human infections [28]. Only two of the cestodes have been reported to infect humans more than just on the rare incidental occasion. $H$. diminuta has occasionally been reported from humans [57-59], and its occurrence in human hosts is linked with the accidental consumption in food of flour beetles, which act as intermediate hosts. There is, however, controversy as to whether the H. nana in rodents is the same or a different species to that infecting humans, although recent data support the lack of infectivity of human isolates in rodents $[60,61]$. The dwarf tapeworm of humans can be common in some human communities [62-65] and it has been recorded in schoolchildren in Kuala Lumpur and other regions of Malaysia in the past [66-68]. Likewise, $H$. diminuta has also been reported from human populations in Malaysia [68], although to our knowledge not from Kuala Lumpur. Given that over a quarter of each of the rat species in both sites were infected with $H$. diminuta, (and as high as $57.5 \%$ of $R$. norvegicus in Bangsar) and similar numbers carried $H$. nana, this must represent a public health risk, especially in the latter case where the life cycle can be direct without involvement of insect intermediate hosts, and therefore contamination of food for human consumption at market and street stalls is a high probability in both sites.

In spite of the high prevalence of $H$. diminuta in $R$. norvegicus in Bangsar, most cestodes were recovered from $R$. rattus, even relatively when sampling effort was taken into account, and this was largely due to the higher abundance of $H$. nana in this host. $H$. nana was the dominant species in 3 of the 4 data-subsets, and the abundance of this cestode in $R$. rattus was almost 3 times as high as that in $R$. norvegicus. The dominance of cestodes in this study does have some precedents in tropical countries. For example, it has been reported that $H$. diminuta was the only helminth recovered from an urban rat population in Qatar [42], but this may have been a consequence of the harsh arid environment in the outskirts of Doha reducing helminth richness and diversity.

Interestingly, nematodes showed a different preference for rat hosts in each of the two sites. Thirty eight percent of all nematodes were recovered from $R$. norvegicus at Bangsar, whilst $47.2 \%$ were from $R$. rattus at Chow Kit, and to a large extent these values were driven by the abundance of $N$. brasiliensis. At Bangsar this species was 12 times more abundant in $R$. norvegicus and in Chow-Kit over 100 times more abundant in $R$. rattus. This again strongly suggests that whilst both species of rats were recovered from both sites, their exact ecological niches did not greatly overlap. $R$. norvegicus generally displace the black rat in areas where humans live. In addition to being larger and more aggressive, the change from wooden structures and thatched roofs, typical of poorer quarters of the city, to bricked and the tiled buildings found at Bangsar, favours the burrowing brown rats over the more arboreal black rats. Moreover, brown rats eat a wider variety of foods, and are more resistant to weather extremes. $N$. brasiliensis is transmitted by infective motile skin penetrating L3 larvae which contaminate the nests and runs that $R$. rattus uses in territories that are more likely to include refuse tips which provide optimum conditions for the survival and hatching of eggs of $N$. brasiliensis. In the cleaner environment of Bangsar, $R$. norvegicus may live in contaminated burrows, while $R$. rattus may avoid comparable levels of exposure by the absence of freely available refuse and its arboreal habits.

The climate in Kuala Lumpur is warm throughout the year with no markedly contrasting seasons comparable to those experienced in temperate climatic zones, but in general there is more rain between October to February and this we have treated as the wet season. Although our analysis detected seasonal effects in some cases, few were independent of interactions with other factors, clearly evident in the summary data and consistent across the three seasonal cycles. One of the exceptions was $M$. muris which showed a higher prevalence in $R$. rattus in all three wet seasons compared to the preceding dry seasons, although a dip in prevalence after a rainy season was not always evident, as for example in the period between cycle 1 and 2. Abundance was also higher in the wet season in the combined data-set and in $R$. norvegicus. Whilst not significant, nor independent of other factors in the case of $R$. norvegicus, a similar pattern of prevalence was evident in cycles 1 and 2 but not 3 (data not shown earlier but in cycle 3 prevalence was very low with only one of the 40 rats caught in the combined dry and wet seasons being infected). Rodents become infected with $M$. muris when they feed on infected intermediate hosts (Orthoptera, Dermaptera and Dictyoptera [69] and even Siphonaptera 
[70]), that harbour the infective L3 stages, and it is conceivable that this seasonal pattern of occurrence in rats was to some extent determined by the availabilty of arthropod hosts and their annual population cycles. A striking seasonal pattern with highest prevalence and abundance of this species in $R$. rattus was recorded in the early autumn and winter periods on North Island of New Zealand, at a season that also coincided with the wetter part of the year [71]. The closely related species $M$. dipodomis showed a higher prevalence in the late summer/autumn period in Dipodomys spp. and Perognathus spp. in New Mexico, USA [72]. However, seasonal differences in prevalence and abundance of other spirurid nematodes have pointed to higher transmission in the summer months (e.g. Pterygodermatites peromysci in Peromyscus leucopus [13]).

A similar pattern relating to abundance was found for the tapeworm $H$. nana, with mean abundance being consistently higher in the wet season in $R$. rattus, and in the first two seasonal cycles in $R$. norvegicus. This species can exploit intermediate hosts such as the tenebrionid beetles but it can also be transmitted directly, since its eggs can hatch in the intestine of rodents and complete the cysticeroid stage in the small intestine as well as the subsequent maturation to fecund adults. The seasonal pattern, however, does suggest that transmission may have been dependent on external sources, but whether egg survival in the dry season was poorer or whether suitable insect hosts were scarce is not known.

The significant seasonal effects detected in $H$. nana and M. muris, largely explained the patterns observed in other parameters used to asses helminth communities when data from all helminths were combined. For example species richness was higher in the wet compared to dry seasons, although in the case of $R$. rattus, the lack of this effect in cycle 3 , led to the loss of the overall seasonal variation when data were combined across 3 cycles. Mean abundance of helminths also increased in the wet season in both hosts, but additionally there was a steady progression of increasing abundance across cycles 1,2 and 3 , suggesting longer-term trends and possibly cycles over a longer time frame than that detectable in a 3 year investigation.

Longer term patterns were evident through the significant differences between cycles, but again in only a few cases did they form clear unidirectional trends over time. Nevertheless, there was a significant trend of increasing helminth diversity in $R$. rattus but not in $R$. norvegicus, suggesting that helminth community structure in the former was changing over time. At the individual species level, the abundance of $H$. spumosum increased with each successive cycle in $R$. rattus but not in $R$. norvegicus, whilst that of $N$. brasiliensis increased in both hosts. Both of these nematodes are monoxenous and therefore do not depend on intermediate hosts, and transmission is by eggs and infective L3 larvae, respectively.

Conversely, there were also some interesting downward trends with time. For example the prevalence of $H$. diminuta drifted downwards with successive cycles in both rat hosts in Bangsar, but not in Chow Kit, suggesting that the transmission was decreasing with time and that the management policy for Bangsar, which is always kept clean, was paying off in terms of disease transmission. With markets combined, abundance also showed a clear decrease with time in $R$. rattus but not in $R$. norvegicus. However, the abundance of $H$. nana fell with successive cycles in $R$. norvegicus but not in $R$. rattus, in which abundance was stable in each of the wet seasons and there was an upward trend with successive dry seasons. Whether these patterns actually represent dynamic changes resulting from changes in the risk of transmission locally or whether they are constituents of longer-term cycles, in both cases driven by biological/ecological factors, or just spurious variation between years is not yet clear, and will only become more apparent when data collection is continued over an even longer period of time.

Helminths are renowned for their chronic long-lasting infections and the poor protective responses that they elicit in their hosts $[73,74]$, and not surprisngly they are often found to accumulate with host age [75]. In our analysis, examples included the increase in helminth diversity and increasing species richness with age in $R$. rattus, increasing prevalence of $H$. spumosum with age in both rats species, increasing abundance of $N$. brasiliensis with age in $R$. norvegicus and increasing prevalence and abundance of $M$. muris in both species of rats. The strongest independent effects of age were observed in the last named species, a stomach dwelling spirurid that is relatively large and robust with a thick cuticle [76]. It takes over 5 weeks to begin laying eggs and is clearly well adapted for long term survival in its host [69].

One species that is known to stimulate potent immunity in its host is H. nana [77], and our data were consistent with this concept in so far as prevalence and abundance declined with host age in both host species, suggesting that after exposure in early life rats became immune to further infection and rejected their earlier acquired worm burdens. There was also some indication that the abundance of $N$. brasiliensis declined in the oldest $R$. rattus, but not in $R$. norvegicus, and this is another species that is known to elicit potent protective immunity in its host $[78,79]$.

Differences between the host sexes in helminth burdens are relatively infrequently observed in naturally infected rodent populations [80]. Here, while we did not find any strong independent effects of host sex on prevalence of any of the species that were examined, there 
were significant differences between the sexes in the overall abundance of helminths. When all helminth species were pooled, male rats harboured more worms than females, but at the individual species level only two showed significant sex effects and in both they were in the opposite direction. Thus female $R$. rattus harboured more $H$. diminuta than males, and more $M$. muris. Where host sex bias has been detected in helminth infections, it has been more often in favour of males which are considered to have weaker immune responses because of the immunodepressive effects of male sex hormones such as testosterone [81-83]. However, female host bias in M. muris has been observed previously [52], although not in all studies [72,84] and in some a bias in the opposite direction has been reported also [71].

\section{Conclusions}

While assessing the role of the two common commensal rat species as reservoirs of helminth infections, we have also explored the role of other intrinsic and extrinsic factors, and in doing so, we were able to take their influence into consideration when interpreting possible differences between the rat hosts. Although $R$. rattus were more common in the present study and represented a greater proportion of the total sample of rats that were analyzed and accounted for most of the helminths, both in terms of species and quantitatively in terms of actual numbers of worms, infections in these hosts were dynamic with significant seasonal and year effects, but nevertheless largely concentrated in rats from the wet market at Chow Kit, where the majority were trapped. In contrast helminth infections in $R$. norvegicus were more stable, less affected by site, although where there was a bias it was in favour of the more affluent site at Bangsar. Both of these two species are commensal urban dwellers, but the parasitological evidence from this study, based on their contrasting patterns of infection, indicates that whilst they share the majority of helminth species that are endemic in the region, they most likely occupy different niches in Kuala Lumpur with limited physical overlap and opportunity for cross infection. We conclude also that nematodes are of little if any significance to the human population, but the two cestode species $H$. diminuta and $H$. nana do represent a health risk, and hence further epidemiological investigations of the parasites of rat populations in other urban sites in Malaysia are required.

\section{Acknowledgements}

We extend our sincere and grateful thanks to the Director and staff of Kuala Lumpur City Hall (DBKL) for their kind co-operation, to the University of Malaya for funding and to the British Council for supporting this research under the Higher Education Links programme. The project was funded by the University of Malaya Research Fund, ref. Vot 438/2000B and 385/2001B.

\section{Author details}

${ }^{1}$ School of Biological Sciences, University of Malaya, 50603 Kuala Lumpur, Malaysia. ${ }^{2}$ School of Biology, University of Nottingham, University Park, Nottingham NG7 2RD, UK. 3School of Biological Sciences, Royal Holloway, University of London, Egham, Surrey, TW20 OEX, UK.

\section{Authors' contributions}

SNMZ and JWL conceived the study. SNMZ collected the data. JMB analysed the data and all three authors wrote the manuscript and approved the final version.

\section{Competing interests}

The authors declare that they have no competing interests.

Received: 13 December 2011 Accepted: 7 March 2012

Published: 7 March 2012

\section{References}

1. Davis $\mathrm{S}$, Calvet $\mathrm{E}$, Leirs $\mathrm{H}$ : Fluctuating rodent populations and risk to humans from rodent-borne zoonoses. Vect Borne Zoonot Dis 2005, 5:305-314.

2. Meerburg BG, Singleton GR, Kijlstra A: Rodent-borne diseases and their risks for pubic health. Crit Rev Microbiol 2009, 35:221-270.

3. Elsheikha HM, Clayton SJ, Yon LK: Parasitic zoonoses at the rodent-captive primate-human health interface. J Egypt Soc Parasitol 2009, 39:447-460.

4. Antoniou M, Psaroulaki A, Toumazos P, Mazeris A, loannou I, Papaprodromou M, Georgiou K, Hristofi N, Patsias A, Loucaides F, Moschandreas J, Tsatsaris A, Tselentis Y: Rats as indicators of the presence and dispersal of pathogens in Cyprus: ectoparasites, parasitic helminths, enteric bacteria, and encephalomyocarditis virus. Vect Borne Zoonot Dis 2010, 10:867-873.

5. Jansen A, Schnieder T: Weil's disease in a rat owner. Lancet Infect Dis 2011, 11:152.

6. Kisielewska K: Ecological organization of intestinal helminth grouping in Clethrionomys glareolus (Schreb.) (Rodentia). V. Some questions concerning helminth groupings in the host individuals. Acta Parasitol Pol 1970, 17:197-208.

7. Lewis JW: Helminth parasites of British rodents and insectivores. Mam Rev 1987, 17:81-93.

8. Webster JP, MacDonald DW: Parasites of wild brown rats (Rattus norvegicus) on UK farms. Parasitology 1995, 111:247-255.

9. Abu-Madi MA, Behnke JM, Lewis JW, Gilbert FS: Descriptive epidemiology of Heligmosomoides polygrus in Apodemus sylvaticus from three contrasting habitats in south-east England. J Helminthol 1998, 72:93-100.

10. Abu-Madi MA, Behnke JM, Lewis JW, Gilbert FS: Seasonal and site specific variation in the component community structure of intestinal helminths in Apodemus sylvaticus from three contrasting habitats in south-east England. J Helminthol 2000, 72:7-15.

11. Behnke JM, Lewis JW, Mohd Zain SN, Gilbert FS: Helminth infections in Apodemus sylvaticus in southern England: interactive effects of host-age, sex and year on prevalence and abundance of infections. J Helminthol 1999, 73:31-44.

12. Behnke JM, Bajer A, Harris PD, Newington L, Pidgeon E, Rowlands G, Sheriff C, Kuliś-Malkowska K, Siński E, Gilbert FS, Barnard CJ: Temporal and between-site variation in helminth communities of bank voles (Myodes glareolus) from N.E. Poland. 2. The infracommunity level. Parasitology 2008, 135:999-1018.

13. Vandegrift KJ, Hudson PJ: Could parasites destabilize mouse populations? The potential role of Pterygodermatites peromysci in the population dynamics of freeliving mice, Peromyscus leucopus. Int J Parasitol 2009, 39:1253-1262.

14. Pederson $A B$, Grieves $T J$ : The interaction of parasites and resources cause crashes in a wild mouse population. J Anim Ecol 2008, 77:370-377.

15. Dunn FL, Lim BL, Yap LF: Endoparasite patterns in mammals of the Malayan Rain Forest. Ecology 1968, 49:1179-1184.

16. Mulkit S, Cheong CK: On a collection of nematode parasites from Malayan Rats. S E Asian J Trop Med Pub Health 1971, 2:516-521.

17. Ow-Yang CK: Studies on the nematode parasite of Malaysian rodents. I. The Rhabdiasidea, Trichuridea and Oxyuridae. J Helminthol 1971, 45:93-109 
18. Lim BL, Lim TW, Cheah W, Yap LF: Angiostrongylus malaysiensis from Tuaran, Sabah, with reference to the distribution of the parasite in Malaysia. S E Asian J Trop Med Pub Health 1976, 7:384-389.

19. Yap LF, DeWitt GF, Krishnasamy M, Sivanandam S, Yen PFK: Protozoan and helminth parasites of small wild mammals in a new Felda Settlement Jenderak Utara, central Pahang, Peninsular Malaysia. S E Asian J Trop Med Pub Health 1977, 8:345-353.

20. Leong TS, Lim BL, Krishnasamy M: Parasite fauna of the house rat Rattus rattus diardii in Kuala Lumpur and nearby villages. S E Asian J Trop Med Pub Health 1979, 10:112-136.

21. Sinniah B: Parasites of some rodents in Malaysia. S E Asian J Trop Med Pub Health 1979, 10:115-121.

22. Krishnasamy M, Singh Kl, Ambu S, Ramachandran P: Seasonal prevalence of the helminth fauna of the wood rat, Rattus tiomanicus (Miller) in West Malaysia. Folia Parasitol 1980, 27:231-235.

23. Inder Singh K, Krishnasamy M, Ho TM: Collection of small vertebrates and their endoparasites from Ulu Endau, Johore, Malaysia. Malay Nat J 1987, 41:349-356.

24. Ambu S, Krishnasamy M, Ramachandran P, Ramos R: Helminth infections of rodents in Orang Asli settlements in Selangor, Malaysia-possible health risks. Trop Biomed 1996, 13:123-127.

25. Paramasvaran S, Krishnasamy M, Lee HL, John J, Lokman H, Naseem BM, Rehana AS, Santhana RJ: Helminth infections in small mammals from Ulu Gombak Forest Reserve and the risk to human health. Trop Biomed 2005, 22:191-194.

26. Syed-Arnez ASK, Mohd Zain SN: A study of wild rats and their endoparasite fauna from Endau Rompin National Park, Johor. Malay J Sci 2006, 25:19-39.

27. Mohd Zain SN: Endoparasites of rodents in two islands of the Straits of Malacca. Malay J Sci 2008, 27:123-127.

28. Paramasvaran S, Sani RA, Hassan L, Hanjeet K, Krishnasamy M, John J, Santhana R, Sumarni MG, Lim KH: Endo-parasite fauna of rodents caught in five wet markets in Kuala Lumpur and its potential zoonotic implications. Trop Biomed 2009, 26:67-72.

29. MacDonald D, Barrett P: Collins Field Guide Mammals of Britain \& Europe London, UK, Harper Collins; 2005.

30. Brooks JE, Rowe FP: Vector control series: rodents, training and information guide World Health Organization, WHO/NBC/87.949; 1987, 107.

31. Rohlf FJ, Sokal RR: Statistical Tables San Franscisco, USA, W.H. Freeman W.H. and Company; 1995.

32. Poulin R: The disparity between observed and uniform distributions: a new look at parasite aggregation. Int J Parasitol 1993, 23:937-944.

33. Elliott JM: Some Methods for the Statistical Analysis of Samples of Benthic Invertebrates Cumbria, UK, Freshwater Biological Association; 1977.

34. Venables WN, Ripley BD: Modern Applied Statistics with S-Plus New York, USA, Springer; 1997.

35. Keymer AE, Dobson AP: The ecology of helminths in populations of small mammals. Mam Rev 1987, 17:105-116.

36. Montgomery SSJ, Montgomery WI: Spatial and temporal variation in the infracommunity structure of helminths of Apodemus sylvaticus (Rodentia: Muridae). Parasitology 1989, 98:145-150.

37. Montgomery SSJ, Montgomery WH: Structure, community and species interactions in helminth communities of wood mice Apodemus sylvaticus. Int J Parasitol 1990, 20:225-242.

38. Gregory RD, Keymer AE, Clarke JR: Genetics, sex and exposure: the ecology of Heligmosomoides polygyrus (Nematoda) in the wood mouse. J Anim Ecol 1990, 59:363-378.

39. Haukisalmi $\mathrm{V}$, Henttonen $\mathrm{H}$ : Coexistence in helminths of the bank vole Clethrionomys glareolus. I. Patterns of co-occurrence. J Anim Ecol 1993, 62:221-229.

40. Haukisalmi $\mathrm{V}$, Hentonnen $\mathrm{H}$ : Analysing interspecific associations in parasites: alternative methods and effects of sampling heterogeneity. Oecologica 1998, 116:565-574.

41. Behnke JM, Gilbert FS, Abu-Madi MA, Lewis JW: Do the helminth parasites of wood mice interact? J Anim Ecol 2005, 74:982-993.

42. Abu-Madi MA, Lewis JW, Mikhail M, El-Nagger ME, Behnke JM: Monospecific helminth and arthropod infections in an urban population of brown rats from Doha, Qatar. J Helminthol 2001, 75:313-320.

43. Myers BJ, Kuntz RE, Wells WH: Helminth parasites of reptiles, birds and mammals in Egypt VII. Check list of nematodes collected from 19481955. Can J Zool 1962, 40:531-538.
44. Zakaria M, Zaghloul TM: Parasitic infection of Rattus norvegicus in Kuwait. Proc First Symp Rec Advs Rodent Control, Kuwait 1982, 136-143.

45. Seong JK, Huh S, Lee JS, Oh YS: Helminths in Rattus norvegicus in Chunchon, Korea. Kor J Parasitol 1995, 33:235-237.

46. Mafiana CF, Osho MB, Sam-Wo-Bo S: Gastrointestinal helminth parasites of the black rat (Rattus rattus) in Abeokuta, southwest Nigeria. $J$ Helminthol 1997, 71:217-220.

47. Zima J, Kral B: Karyotypes of European Mammals,2. Acta Sci Nat Acad Sci Bohem 1984, 18:62.

48. Corbet GB, Harris S: The Handbook of British Mammals Oxford, UK, Blackwell; 1991, 588.

49. Poulin R: Macroecological patterns of species richness in parasite assemblages. Basic Appl Ecol 2004, 5:423-434.

50. Walther BA, Morand S: Comparative performance of species richness estimation methods. Parasitology 1998, 116:395-405.

51. Feliu C, Renaud F, Catzeflis F, Hugot J-P, Durand P, Morand S: A comparative analysis of parasite species richness of Iberian rodents. Parasitology 1997, 115:453-466.

52. Wertheim G: Helminth parasites of the rat Rattus norvegicus from Haifa and Tel-Aviv. Bull Res Council Isreal 1963, 10E:125-129.

53. Verster A: A taxonomic revision of the genus Taenia Linnaeus, $1758 \mathrm{~S}$. Str. Onderstepoort J Vet Res 1969, 36:3-58.

54. Gillespie SH: The epidemiology of Toxocara canis . Parasitology Today 1988, 4:180-182.

55. Hildebrand J, Zalesny G, Okulewicz A, Baskkiewicz K: Preliminary studies on the zoonotic importance of rodents as a reservoir of toxocariasis from recreation grounds in Wroclaw,Poland. Helminthologia 2009, 46:80-84.

56. Moravec F: Proposal of a new systematic arrangement of nematodes of the family Capillariidae. Folia Parasitol 1982, 29:119-132.

57. Owen IL: Parasitic zoonoses in Papua New Guinea. J Helminthol 2005, 79:1-14.

58. Chomel BB: Zoonoses of house pets other than dogs, cat and birds. Ped Infs Dis J 1992, 11:479-487.

59. Tena D, Simon MP, Gimeno C, Pomata MTP, Illescas S, Amondarain I, Gonzales A, Dominguez J, Bisquert J: Human infection with Hymenolepis diminuta: case report from Spain. J Clin Microbiol 1998, 36:2375-2376.

60. MacNish MG, Morgan UM, Behnke JM, Thompson RCA: Failure to infect laboratory rodent hosts with human isolates of Rodentolepis (= Hymenolepis) nana. J Helminthol 2002, 76:37-43.

61. MacNish MG, Morgan-Ryan UM, Monis PT, Behnke JM, Thompson RCA: A molecular phylogeny of nuclear and mitochondrial sequences in Hymenolepis nana (Cestoda) supports the existence of a cryptic species. Parasitology 2002, 125:567-575.

62. Welch JS: Parasitology field studies. Twenty seventh Annual Report of the Queensland Inst Medl Res, Brisbane 1972, 22-23.

63. Reynoldson JA, Behnke JM, Pallant LJ, MacNish MG, Gilbert F, Thompson RAC: Failure of pyrantel in treatment of human hookworm infections (Ancylostoma duodenale) in the Kimbereley region of north west Australia. Acta Tropica 1997, 68:301-312.

64. Brandt LJ: Commentary. Gastrointest Endoscopy 2009, 70:785

65. Ragunathan L, Kalivaradhan SK, Ramadass S, Nagaraj M, Ramesh K: Helminthic infections in school children in Puducherry, South India. J Microbiol Immunol Infect 2010, 43:228-32.

66. Sinniah B: Prevalence, treatment and reinfection of intestinal helminths among schoolchildren in Kuala Lumpur, Malaysia. Pub Health 2005, 98:38-42.

67. Sagin DD, Mohamed M, Ismail G, Jok JJ, Lim LH, Pui JNF: Intestinal parasitic infection among five interior commuities at Ipper Rejang River, Sarawak, Malaysia. SE Asian J Trop Med Pub Health 2002, 33:18-22.

68. Sinniah $B$, Sinniah D, Singh M, Poon GK: Prevalence of parasitic infections in Malaysian oil palm estate workers. SE Asian J Trop Med Pub Health 1978, 9:272-276.

69. Quentin JC: Morphogenese larvarie du spiruride Mastophorus muris (Gmelin, 1790). Ann Parasitol (Paris) 1970, 45:839-855.

70. Beaucournu JC, Chabaud AG: Infestation spontanée de Puces par le spiruride Mastophorus muris (Gmelin). Ann Parasitole (Paris) 1963, 38:931-934.

71. Charleston WAG, Innes JG: Seasonal trends in the prevalence and intensity of spiruroid nematode infections of Rattus $r$. rattus. New Zealand J Zool 1980, 7:141-145. 
72. Decker KH, Duszynski DW, Patrick MJ: Biotic and abiotic effects on endoparasites infecting Dipodomys and perognathus species. J Parasitol 2001, 87:300-307.

73. Behnke JM: Evasion of immunity by nematode parasites causing chronic infections. Adv Parasitol 1987, 26:1-70.

74. Maizels RM, Balic A, Gomez-Escobar N, Nair M, Taylor MD, Allen JE: Helminth parasites - masters of regulation. Immunol Rev 2004, 201:89-116.

75. Andreassen J, Bennet-Jenkin EM, Bryant C: Immunology and biochemistry of Hymenolepis diminuta. Adv in Parasitol 1999, 42:223-275.

76. Hamada GS, Wertheim G: Mastophorus muris (Nematoda: spirurina): cuticular ultrastructure of the adult and third stage larva. J. Parasitol 1978, 64:448-558.

77. Isaak DD, Jacobson RH, Reed ND: The course of Hymenolepis nana infections in thymus-deficient mice. Int Arch Allergy Appld Immunol 1977 55:504-513.

78. Rothwell TLW: Immune expulsion of parasitic nematodes from the alimentary tract. Int J Parasitol 1989, 19:139-168.

79. Else KJ, Finkelman FD: Intestinal nematode parasites, cytokines and effector mechanisms. Int J Parasitol 1998, 28:1145-1158.

80. Gregory RD: On the interpretation of host-parasite ecology: Heligmosomoides polygyrus (Nematoda) in wild wood mouse (Apodemus sylvaticus) populations. J Zool 1992, 226:109-121.

81. Ferrari N, Cattadori IM, Nespereira J, Rizzoli A, Hudson PJ: The role of host sex in parasite dynamics: field experiments on the yellow-necked mouse Apodemus flavicollis. Ecol Let 2004, 7:88-94.

82. Luong LT, Grear DA, Hudson PJ: Male hosts are responsible for the transmission of a trophically transmitted parasite, Pterygodermatites peromysci, to the intermediate host in the absence of sex-biased infection. Int J Parasitol 2009, 39:1263-1268.

83. Poulin R: Sexual inequalities in helminth infections: a cost of being a male? Am Nat 1996, 147:287-295.

84. Nasher AK: Helminths of Saudi Arabia. Helminth parasites of the spiny mouse Acomys dimidiatus (Cretzschmar) from southwest Saudi Arabia. Fauna Saudi Arabia 1984, 6:127-129.

doi:10.1186/1756-3305-5-47

Cite this article as: Mohd Zain et al:: Helminth communities from two urban rat populations in Kuala Lumpur, Malaysia. Parasites \& Vectors 2012 $5: 47$.

\section{Submit your next manuscript to BioMed Central and take full advantage of:}

- Convenient online submission

- Thorough peer review

- No space constraints or color figure charges

- Immediate publication on acceptance

- Inclusion in PubMed, CAS, Scopus and Google Scholar

- Research which is freely available for redistribution 